Document downloaded from:

http://hdl.handle.net/10251/142685

This paper must be cited as:

Macian Martinez, V.; Bermúdez, V.; Villalta-Lara, D.; Soto-Izquierdo, L. (25-1). Effects of low-pressure EGR on gaseous emissions and particle size distribution from a dual-mode dual-fuel (DMDF) concept in a medium-duty engine. Applied Thermal Engineering. 163:1-15. https://doi.org/10.1016/j.applthermaleng.2019.114245

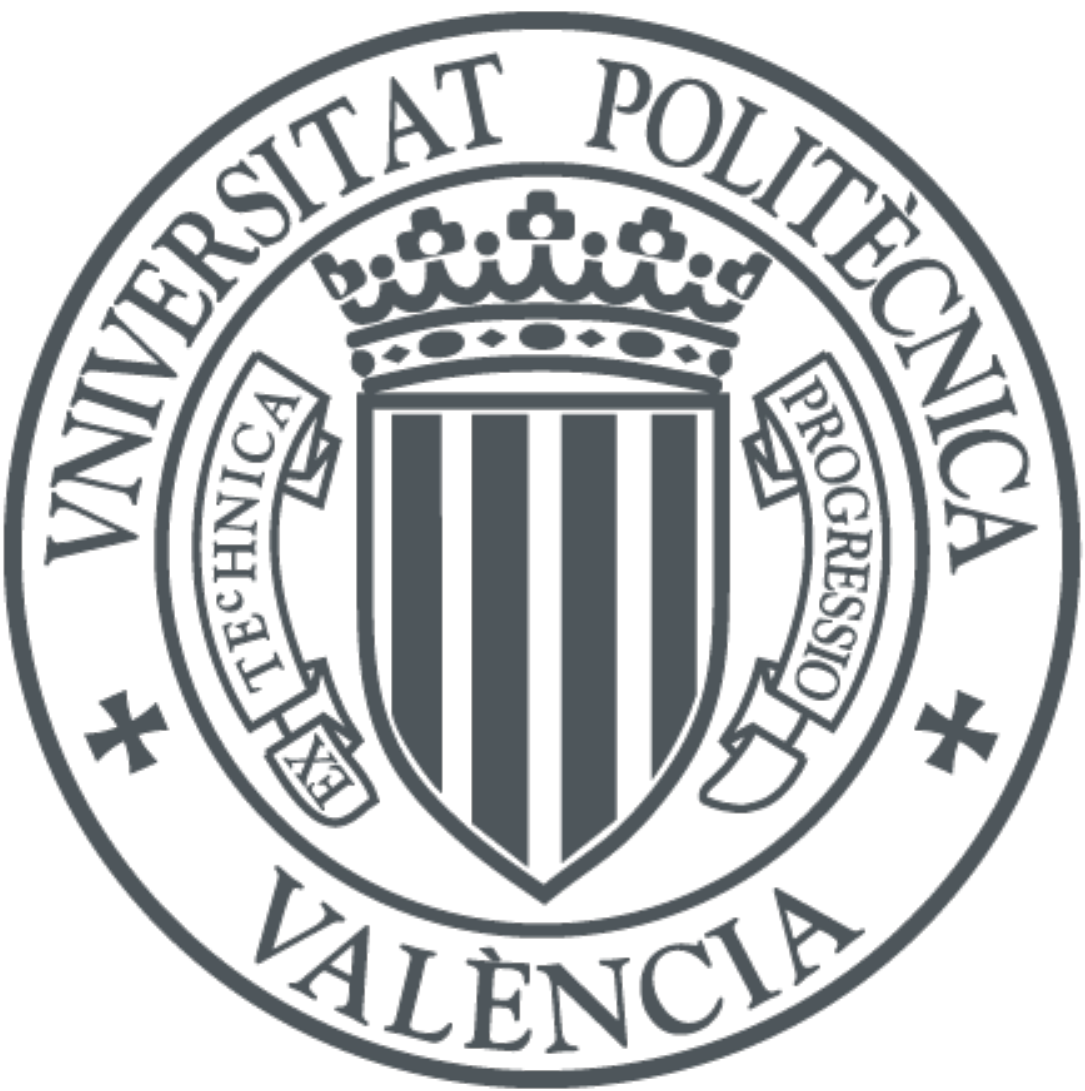

The final publication is available at

https://doi.org/10.1016/j.applthermaleng.2019.114245

Copyright Elsevier

Additional Information 


\title{
Effects of low-pressure EGR on gaseous emissions and particle size distribution from a dual-mode dual-fuel (DMDF) concept in a medium-duty engine.
}

\author{
Vicente Macián, Vicente Bermúdez*, David Villalta and Lian Soto \\ Universitat Politècnica de València, CMT-Motores Térmicos, Camino de Vera s/n, 46022 Valencia, Spain. \\ *Corresponding author. Tel.: +34 96387-9652; E-mail: bermudez@mot.upv.es
}

\section{Highlights}

- The EGR rate is the key to the dual-mode dual-fuel concept development

- The NOx and PM emissions are lower at dual-mode dual-fuel than conventional diesel

- Increasing EGR increases the accumulation-mode particles at dual-mode dual-fuel

- At high loads, the EGR increases the accumulation-mode particles at dual-mode dual-fuel

- At low load, the nucleation-mode particles and $\mathrm{HC}$ emission increases at dual-mode dual-fuel

\begin{abstract}
The application of a low-temperature combustion concept, such as RCCI combustion under real engine operating conditions is extremely complex. However, the implementation of the dual-mode dual-fuel (DMDF) strategy allows operating in low-medium load with the RCCI combustion and in high load with dual-fuel diffusive combustion. This allows taking advantage of the benefits of RCCI combustion as the simultaneous reduction of PM and NOx emissions. However, there are still serious challenges that required to solve, such as the high-pressure rise rate and the excessive $\mathrm{CO}$ and $\mathrm{HC}$ emissions. In this sense, this work shows how the implementation and an adequate adjustment of the cooled LP-EGR rate significantly minimize these problems and also shows how the LP-EGR has a greater impact on the DMDF than on the CDC concept.

This work has been performed in a modern medium-duty diesel engine fueled with standard gasoline and diesel fuels, with which a cooled LP-EGR loop has been coupled. A TSI Scanning Particle Sizer (SMPS 3936L75) was used to measure the particles size distribution and the Horiba MEXA-ONE-D1-EGR gas analyzer system to determine gaseous emissions. A parametric variation of the LP-EGR rate was experimentally performed to analyze the effect over each combustion process that encompasses the DMDF concept (fully premixed RCCI, highly premixed RCCI and dual-fuel diffusion) and its consequent impact on gaseous and particle emissions. In addition, results were compared against the CDC concept to state the benefits of the DMDF concept. Among the different results obtained, it can be highlighted that during the RCCI strategy the increase in LP-EGR rate provided a reduction in NOx emissions. Nonetheless, unlike that fully premixed RCCI in highly premixed RCCI combustion, the PM emissions increased with this increment in the LP-EGR rate, shifting the size distribution of particle toward larger sizes, but decreasing the $\mathrm{HC}$ and $\mathrm{CO}$ emissions. Finally, with the exception of the high $\mathrm{HC}$ and $\mathrm{CO}$ emissions in fully premixed RCCI, in all the combustion strategies of the DMDF concept, a reduction of the analyzed pollutants was observed when compared with the CDC mode.
\end{abstract}

Keywords: Dual-fuel combustion, Reactivity controlled compression ignition, low-pressure EGR, Gaseous emissions and Particle size distribution 


\section{Abbreviations}

aTDC after top dead center

CA10 crank angle for $10 \%$ of fuel burnt

CA50 crank angle for $50 \%$ of fuel burnt

CA90 crank angle for $90 \%$ of fuel burnt

CA90-CA10 combustion duration

CDC Conventional Diesel Combustion

CI compression-ignition

DI direct injection

DMDF dual-mode dual-fuel

GF gasoline fraction

Ign. Delay ignition delay

Ind. Eff indicated efficiency

HCCI homogeneous charge compression ignition

IMEP indicated mean effective pressure

IP injection pressure

LP-EGR low-pressure EGR

\begin{tabular}{ll} 
LTC & low temperature combustion \\
Mix. Time & \multicolumn{1}{c}{ diesel mixing time } \\
$\mathrm{m}_{\text {total_air }} \quad$ total air mass flow \\
$\mathrm{m}_{\text {total_fuel }} \quad$ total fuel mass flow \\
Pcyl & cylinder pressure \\
PFI & port fuel injection \\
PPCI & premixed charge compression ignition \\
PM & particulate matter \\
PRR & pressure rise rate \\
PSD & particle size distribution \\
RON & research octane number \\
RoHR & rate of heat release \\
RCCI & reactivity-controlled compression ignition \\
SOI & start of the injection \\
SoC & start of combustion
\end{tabular}

LTC low temperature combustion

$\mathrm{m}_{\text {total air } \quad \text { total air mass flow }}$

$\mathrm{m}_{\text {total_fuel total fuel mass flow }}$

cylinder pressure

port fuel injection

PM particulate matter

PRR pressure rise rate

PSD particle size distribution

RON research octane number

SoC start of combustion

\section{Introduction}

The main technological challenge for the compression ignition (CI) diesel engine is to maintain its competitive advantage in terms of efficiency, and therefore, fuel consumption, compared to the spark ignition (SI) gasoline engine. This is due to the need of these engines to comply with the new standard regulations, which are particularly severe in terms of NOx and particulate matter (PM) emissions [1]. A relevant progress has been made especially on common rail high-speed direct injection (HSDI) systems, advanced turbo-charging, cooled exhaust gas recirculation (EGR), optimized combustion chamber and nozzle design, as well as sophisticated control algorithms $[2,3]$. However, the conventional diesel combustion (CDC) taking place in a direct injection (DI) diesel engine, where injection, evaporation, mixture preparation and combustion occur almost simultaneously, leads to very different local condition in terms of temperature and air/fuel ratio, promoting the formation of both NOx and particles. The PM and NOx emissions can be individually suppressed, but it exists a clear trade-off when trying to reduce both emissions simultaneously. This fact means it is necessary to study new combustion strategies to reduce the emissions of CI engines. Many of these advanced combustion strategies can be classified as low temperature combustion (LTC) concepts that work with a higher degree of premix and lower combustion temperatures. Among these concepts are the homogeneous-charge compression ignition (HCCI) [4,5], the premixed charge compression ignition (PCCI) [6,7] and the reactivity controlled compression ignition (RCCI) [8]. The absence of a diffusion flame in the LTC concepts provides a reduction in particle formation, while the NOx formation is limited using high EGR levels.

Following this approach, the RCCI combustion can be considered as one of the most promising concepts of LTC strategies. The RCCI engine presents a dual fuel injection system. A port fuel injection (PFI) is used to inject the low reactivity fuel (low cetane number) at the intake manifold in order to create a homogeneous mixture. Hence, the homogeneous mixture formed is compressed by the piston during the compression stroke, during this phase, the high reactivity fuel (high cetane number) is injected through the direct injector placed at the cylinder head and can be injected in more than one event. Once the mixture is compressed, the conditions at the combustion chamber will determine the autoignition of the mixture between low reactivity fuel, high reactivity fuel, fresh air and EGR rate [9]. Therefore, by varying the relative amounts or injection timings of the two fuels, it is possible to create different fuel blends in order to adjust the combustion phasing [10]. However, the pressure rise rate appears to be a limitation when increasing the engine load [11]. High pressure rise rate (PRR) could exceed the mechanical constraints causing severe damage to the engine hardware. Thus, limiting or reducing the PRR contributes to increasing the engine operating range towards the full load operation.

In this sense, J. Benajes et al. [12] have proposed the dual-mode dual-fuel (DMDF) concept in order to enhance the range of operation of the engine. Hence, DMDF is based on dual fuel premixed combustion strategies such as the RCCI concept. The combustion strategy of the DMDF concept is modified as the engine load is increased. Hence, during the low load operation, the concept uses a fully premixed RCCI strategy. From medium load, the concept switches to highly premixed RCCI and dual-fuel diffusive strategy up to full load operation. The stability and control of combustion in each of the strategies depend mainly on the low reactivity/high reactivity fuel ratio, the injection settings and the EGR rate [13]. In this sense, in RCCI operation, a high EGR rate and two diesel injections are used during the compression-stroke, where the last injection advances towards the top dead center (TDC) and decreases the EGR rate as the load increases. Already, in high 
load, for the dual-fuel diffusive strategy, it is shifted to a single diesel injection near the TDC and the EGR rate is considerably reduced, causing the combustion behavior to be more diffusive-like. The possibility of reducing the EGR rate is one of the main advantages of the DMDF concept, considering that in the RCCI strategy the use of massive EGR rates over the whole engine operation map is indispensable [11]. Hence, the EGR loop, turbocharger and cooler need to be redesigned compared with the stock CDC hardware.

The EGR is the most effective method of reducing the combustion temperatures while avoiding the NOx formation. However, the displacement of part of the fresh air by exhaust gas causes the equivalence ratio to increase, leading to a trade-off between NOx and PM emissions. Moreover, the increase of the intake charge temperature when using conventional EGR leads to substantial decrease in ignition delay, also increasing PM emissions [14]. To avoid this effect, the exhaust gas is cooled before being recirculated to the combustion chamber, which provides additional benefits by lowering NOx emissions to a greater extent. In addition, the use of cooled EGR improves the volumetric efficiency and therefore increases the power density of the engine as compared to non-cooled EGR.

In this scenario, some works that study the benefits of combining fuel blends with the EGR can be found. The experiments carried out by J. Gong et al. [15] on an SI engine fueled with various iso-propanol/gasoline blends showed an increased in the PN emissions when the volume fraction of iso-propanol in the blend increased. However, the concentration of the particles decreased considerably with the increased of the EGR rate, in conditions of mixture rich in iso-propanol, making viable the use of iso-propanol and its benefits, among which are the decrease in NOx emissions.

$\mathrm{X}$. Gu et al. [16] observed a slight increase in $\mathrm{HC}$ and $\mathrm{CO}$ emissions with the EGR addition in an SI engine fueled with n-butanol/gasoline blends. However, the EGR provided a simultaneous reduction of NOx and PM emissions, behavior that was more marked as the EGR rate increased.

The results of G. Duraisamy et al. [17] research on RCCI engine during the operation with a methanol/diesel blend showed that the introduction of EGR reduced the NOx and PM emissions further in RCCI combustion compared to RCCI without EGR operation. However, the higher EGR rate increased the HC and $\mathrm{CO}$ emissions than CDC operation. Therefore, a moderate EGR rate is recommended to obtain an optimal level of performance and emissions.

Furthermore, in PM emissions terms, V.Y. Prikhodko et al. [18] compared the results of filter smoke numbers (FSN) and PM filter mass measurements under RCCI operation mode, showing that RCCI PM is mostly organic carbon with almost no elemental carbon. Despite of having some correlations between FSN measurement and soot mass for PCCI operation [19], for RCCI is not possible to convert FSN in PM because most part of the particles come from soluble organic fraction (nucleation-mode particles), which is not captured by the Smokemeter [20]. Since the DMDF mode relies on RCCI combustion in the major portion of the engine map, this behavior should be also studied.

Considering the previously described background, the aim of this paper is to experimentally evaluate the impact of different cooled low pressure (LP) EGR rates in each combustion process that encompasses the DMDF concept and its consequent impact on gaseous and particle emissions including its size distribution in a mediumduty diesel engine fueled with standard gasoline and diesel fuels. Therefore, considering the significant importance of the EGR in the RCCI combustion and in general in the dual-fuel strategies, this work will be able to provide relevant information to optimize the DMDF concept and finally make viable its implementation in real operating conditions. This experimental study will also include a comparison between the two models, the DMDF and the CDC. For this, a parametric study based on the independent modification of the LP-EGR was carried out in four operating points at different engine speed and load in order to cover the whole engine map and the combustion strategies of the DMDF concept (fully premixed RCCI, highly premixed RCCI and dualfuel diffusion) and in equivalent points but during the CDC operation.

\section{Material and methods}

\subsection{Test cell and engine description}

The experiments presented in this work are conducted in a single-cylinder engine. By contrast, the engine is not a conventional single-cylinder engine research engine, it is a hybrid solution between a multi-cylinder engine and a single-cylinder engine. Indeed, this solution allows the use of a single-cylinder engine but with a more cost-effective way to implement this type of engines. The single-cylinder engine used derives from a commercial medium-duty engine. The stock engine is a VOLVO D5K with 4 in-line cylinders developed for urban freight distribution purposes. Main specifications of the engine are shown in Table 1. 
Table 1. Main characteristics of the base engine.

\begin{tabular}{l|l}
\hline Characteristic & Value \\
\hline Style & 4 stroke, DI diesel engine \\
OEM EVO calibration & EURO VI \\
Maximum power & $177 \mathrm{~kW} @ 2200 \mathrm{rpm}$ \\
Maximum brake torque & $900 \mathrm{Nm} @ 1200-1600 \mathrm{rpm}$ \\
Maximum in-cylinder pressure & $190 \mathrm{bar}$ \\
Maximum injection pressure & $2000 \mathrm{bar}$ \\
Bore x Stroke & $110 \mathrm{~mm}$ x 135mm \\
Connecting rod length & $212.5 \mathrm{~mm}$ \\
Crank length & $67.5 \mathrm{~mm}$ \\
Total displaced volume & $5100 \mathrm{~cm} 3$ \\
Number of cylinders & 4 \\
Compression ratio & $15.3: 1$ \\
\hline
\end{tabular}

From the engine operation standpoint, both engines are operated at the same time. The single-cylinder engine is operated under dual-fuel strategies and the other three cylinders are operated under CDC. In this sense, the three remaining cylinders are driven by the original engine control unit (ECU) with the aim to balance the cylinder-to-cylinder maximum pressure and load. With this method of engine operation, it is expected to preserve the engine integrity avoiding excessive internal stress at the crankshaft that could break it.

Fig. 1 presents the scheme of the test bench, including the engine and all the equipment required to carry out the test campaign. From the figure, it is seen that the after-treatment system has been removed, and the single-cylinder is not using the stock turbocharger system or the stock short route HP-EGR. Thus, a fresh air loop and a cooled LP-EGR loop has been coupled to provide the desired air management conditions at the single-cylinder. The intake required fresh air is provided by a screw compressor that provides compressed air from 1 to 3.7 bar. After the dryer, the exact air mass flow is measured by means of a volumetric flow meter (G100 RVG). The exhaust line is equipped with a back-pressure valve that generates the desired exhaust pressure by the engine operation point. This back-pressure valve contributes to the LP-EGR loop as well. Between the valve and the exhaust pipes it is located a settling chamber in order to mitigate the pressure valves generated by the single-cylinder. The size of the settling chamber is the same as the settling chamber placed at the intake line. The test bench was fully equipped with $\mathrm{K}$ thermocouples and mean pressure sensors in the exhaust, cooling, intake and lubricating system. Finally, the engine was connected to an AVL-APA 404 asynchronous dynamometer.

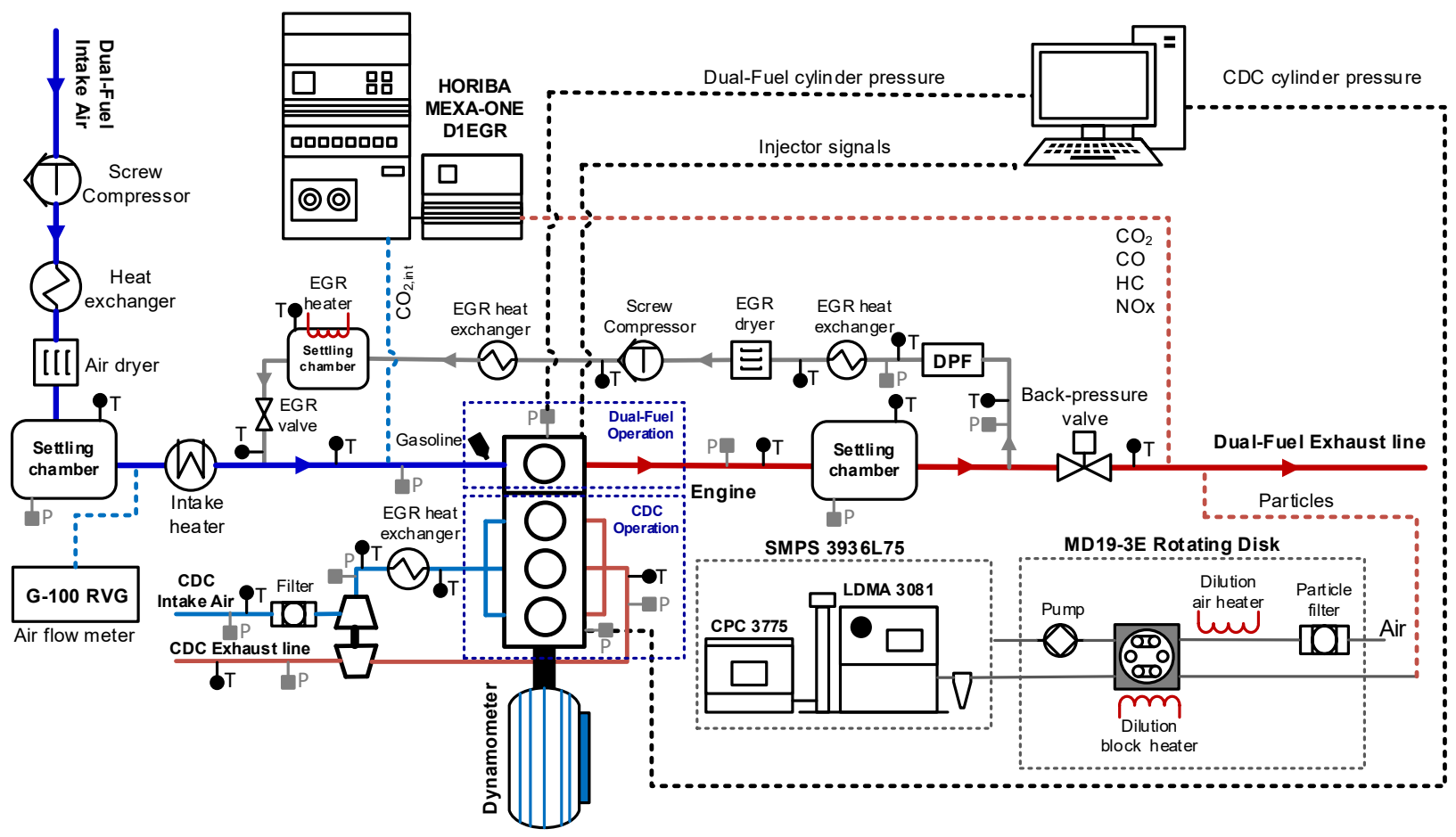

Fig. 1. Scheme of the test bench.

The cooled LP-EGR system is similar, at least in concepts, as the intake line. It contains a DPF to remove the soot particles from the exhaust gases, a cooler to reduce the exhaust temperature and a water decanter to 
remove the condensates. The EGR flow connects directly to the EGR settling chamber (100 liters) in order to mitigate the possible pressure waves provided by the compressor. Finally, the LP-EGR system provides an EGR flow according to the desired pressure, temperature and humidity desired conditions. Both EGR and fresh air flows are sent to the mixer prior to the intake manifold. Hence, the air mixture between EGR and fresh air is homogeneous at the intake manifold.

Dual-fuel strategies requires a double injection system. Particularly in this investigation, the injection scheme uses a hybrid solution with a DI for the diesel fuel and a PFI for the gasoline fuel. A common-rail injection system with a solenoid injector was used to inject the diesel fuel directly into the cylinder. Concerning the gasoline injection, the PFI was placed at the intake manifold and was specified to be able to deliver all the gasoline mass into the cylinder during the intake-stroke. The main characteristics of the diesel and gasoline injectors are depicted in Table 2. The fuel mass flow is measured by an AVL 733S fuel balance.

Table 2. Diesel and gasoline fuel injector characteristics.

\begin{tabular}{ll|ll}
\hline Diesel injector & & Gasoline injector & Saturated \\
\hline Actuation type & Solenoid & Injector style & 980 \\
Steady flow rate $@ \mathbf{1 0 0}$ bar $\left[\mathbf{c m}^{\mathbf{3}} / \mathbf{m i n}\right]$ & 1300 & Steady flow rate $\mathbf{a} \mathbf{3} \mathbf{b a r}\left[\mathbf{c m}^{\mathbf{3}} / \mathbf{m i n}\right]$ & 30 \\
Number of holes & 7 & Included spray angle $\left[{ }^{\circ}\right]$ & 5.5 \\
Hole diameter $[\boldsymbol{\mu m}]$ & 177 & Injector pressure $[\mathbf{b a r}]$ & Single \\
Included spray angle $\left[{ }^{\circ}\right]$ & 150 & Injection strategy & \\
\hline
\end{tabular}

The fuels used during the experiments were obtained directly from the regular service station. Hence, the high reactivity fuel used was diesel (EN 590) and the low reactivity fuel used was gasoline 95 research octane number (RON) (EN 228). Main physicochemical properties are presented in Table 3.

The fuels used during the experiments were obtained directly from the regular petrol station. Hence, the high reactivity fuel used was diesel and the low reactivity fuel used was gasoline 95 research octane number (RON). The main physicochemical properties of both fuels are listed in Table 3. All the properties were obtained following European standards, specifically, the standards used were EN 228 for gasoline [21] and EN 590 for diesel [22].

Table 3. Physical and chemical properties of the different fuels used.

\begin{tabular}{l|ll|ll}
\hline Properties & Diesel & Test Method & Gasoline & Test Method \\
\hline Density $[\mathbf{k g} / \mathbf{m 3}]\left(\mathbf{T}=\mathbf{1 5}^{\circ} \mathbf{C}\right)$ & $\mathbf{8 2 0}$ & EN ISO 3675 & $\mathbf{7 2 0}$ & EN ISO 3675 \\
Viscosity $[\mathbf{c m} \mathbf{2} / \mathbf{s}]\left(\mathbf{T}=\mathbf{4 0}^{\circ} \mathbf{C}\right)$ & $\mathbf{2 . 8}$ & EN ISO 3104 & - & \\
RON [-] & - & & $\mathbf{9 5 . 0}$ & EN ISO 5164 \\
MON[-] & - & & $\mathbf{8 5 . 0}$ & EN ISO 5163 \\
Cetane number [-] & $>\mathbf{5 1}$ & EN ISO 5165 & - & \\
Oxidation stability [min] & $\mathbf{1 2 0 0}$ & EN 15751 & $\mathbf{3 6 0}$ & EN ISO 7536 \\
\hline
\end{tabular}

The engine control is done by a real time National Instruments powertrain control system with two controllers, combining a field-programmable gate array (FPGA) based synchronization of the injection, and a peripheral component interconnect (PCI) extensions for instrumentation (PXI) system is used for the in-cylinder pressure acquisition and processing. The control software was developed in-house and allows performing transitions between different injection conditions, and a closed loop control of the combustion characteristics. This control allows operating at the same engine point while the fuel blend is modified in function of the air management variations.

The equipment used for the gaseous compounds measurement is the Horiba MEXA-ONE-D1-EGR analyzer. The five-gas Horiba analyzer accounts the molar fraction of $\mathrm{NO}, \mathrm{NO}_{2}, \mathrm{CO}$, unburned $\mathrm{HC}, \mathrm{CO}_{2}$ and $\mathrm{O}_{2}$. The sample acquired by the equipment flows towards the analyzer through a heated line $\left(\approx 190{ }^{\circ} \mathrm{C}\right)$ in order to avoid condensation of the $\mathrm{HC}$ species. Every specie of the exhaust gases is analyzed by a specific device. Full description of the different measuring principles are provided in SAE standard [23].

A single-stage dilution system was coupled with a scanning mobility particle sizer (SMPS) to measure particle size distributions (PSD). The dilution system used in this study was an MD19-3E Rotating Disk, which uses a unique rotating disk method to dilute a sample for particle measurement. Two disks, one with eight and the other with ten cavities allows to select a dilution ratio from 15:1 to 3000:1. A portion of the raw exhaust is captured by each cavity of the rotating disk and is mixed with preheated and filtered dilution air.

In the MD19-3E RD, the dilution unit and the dilution air can be heated up to selectable temperatures of $200{ }^{\circ} \mathrm{C}$. This method keeps liquids evaporated above their dew point, during and after dilution, and prevents generation of volatile nanoparticles by nucleation. This thermal conditioning of the sample allows for the 
reduction of the concentration range within the acceptable limits of the particle measuring device and provides accurate information on the concentration of particles generated during the combustion process. The advantages of this dilution system can be analyzed in more detail in previous study by the authors M. Kasper et al. [24].

TSI Scanning Particle Sizer (SMPS 3936L75) was used to measure the PSD. This system is equipped with an inertial impactor to remove particles larger than $1 \mu \mathrm{m}$; as well as a Long Differential Mobility Analyzer (LDMA 3081) to select the particle size to be measured, with a range from 2.5 to $1000 \mathrm{~nm}$ and a Condensation Particle Counter (CPC 3775) to count particles with sizes down to $4 \mathrm{~nm}$. To obtain reliable values, the measurement methodology developed by J.M. Desantes et al. [25] was used in this study to dilute the exhaust sample and to measure PSD. The accuracy of the instrumentation used in the test cell is summarized in Table 4.

Table 4. Accuracy of the instrumentation used in the test cell.

\begin{tabular}{l|l|l|l}
\hline Device & Manufacturer and model & Variable measured & Accuracy \\
\hline Air flow meter & Elster RVG G100 & Fresh air mass flow & $\pm 0.1 \%$ \\
Fuel balance & AVL 733S & Gasoline/diesel fuel mass flow & $\pm 0.2 \%$ \\
Gas analyzer & Horiba MEXA-ONE-D1-EGR & NOx, CO, HC, CO, $\mathrm{O}_{2}$ & $4 \%$ \\
SMPS & TSI SMPS-3936L75 & Particles number and size & $3.5 \%$ \\
Piezoelectric transducer & Kistler 6125C & In-cylinder pressure & $\pm 1.25 \mathrm{bar}$ \\
Piezoelectric transducer & Kistler 4045A10 & Intake/exhaust pressure & $\pm 25 \mathrm{mbar}$ \\
Thermocouple & TC direct type K & Intake/exhaust tmperature & $\pm 2.5^{\circ} \mathrm{C}$ \\
\hline
\end{tabular}

\subsection{Theoretical tools and calculations method}

To achieve the desired load in the DMDF operation, an adequate adjustment of the injection parameters, EGR rate and gasoline/diesel ratio or gasoline fraction (GF) is necessary. In this sense, the GF (Eq. (1)) exerts a great influence on the mixture reactivity and consequently on the SoC. Therefore, when adding gasoline, the GF will increase, and the mixture reactivity will decrease, delaying the combustion process with respect to the TDC.

$$
G F[\%]=\frac{m_{\text {gasoline }}}{m_{\text {gasoline }}+m_{\text {diesel }}} \cdot 100
$$

The EGR rate is obtained taking in account the $\mathrm{CO}_{2}$ at the intake and at the exhaust and the atmospheric content of $\mathrm{CO}_{2}$. Hence, the EGR rate is calculated according to Eq. (2), where $\mathrm{CO}_{2 \text { atmospheric }}$ is equal to $400 \mathrm{ppm}$ [26].

$$
E G R[\%]=\frac{\mathrm{CO}_{\text {2intake }}-\mathrm{CO}_{\text {2atmospheric }}}{\mathrm{CO}_{\text {2exhaust }}-\mathrm{CO}_{2 \text { atmospheric }}} \cdot 100
$$

The combustion analysis was carried out with an in-house 0-D thermodynamic model called CALMEC. The theoretical principles of this 0-D model are based on applying the first law of thermodynamics to solve open systems considering the fuel injection and blow-by flow. This diagnostic model uses the in-cylinder pressure signal and the mean variables recorded during the experiments (engine speed, coolant, oil, intake and exhaust temperatures, air, EGR and fuel mass flow) as its main inputs, to obtain a wide variety of combustion parameters, such as the rate of heat release (RoHR), bulk gas temperatures, main combustion phases (CA10, CA50 and CA90: crank angle after TDC (CA aTDC) in which the $10 \%, 50 \%$, and $90 \%$ of the total heat release has been released during the combustion process, respectively), indicated mean effective pressure (IMEP) and indicated efficiency (Ind. Eff). The full description of the model can be found in F. Pairy et al. [27].

In addition, the combustion duration (CA90-CA10) was determined, which is defined as the time elapsed from the start of combustion (SoC) (represented by the CA10) up to the end of the combustion (represented by the CA90). The diesel mixing time (Mix. Time) and the ignition delay (Ign. Delay) were calculated by equation (3) and (4) respectively. As can be seen in the equation (3), the Mix. Time determines the interval between the end of fuel injection (EoI) of the last diesel injection and the SoC, while the Ign. Delay in equation (4) determines the interval between the start of the injection (SoI) of the last injection and the SoC. It is important to consider that an increase in Mix. Time positive values, results in leaner equivalence ratios at SOC. However, the negative values of Mix. Time or Ign. Delay indicate the coexistence of fuel injection and the combustion process during a certain period, which will be higher while the Mix. Time are lower (or greater in absolute value).

$$
\begin{aligned}
& \text { Mix. Time }=S o C-E_{\text {Last injection }} \\
& \text { Ign. Delay }=S o C-\text { SoI }_{\text {last injection }}
\end{aligned}
$$


Finally, the combustion efficiency (Comb. Eff) is calculated by $\mathrm{CO}$, unburned $\mathrm{HC}$ and total fuel mass flow ( $\mathrm{m}_{\text {tota_fuel }}$ ), according to Eq. (5) [28].

$$
\text { Comb.Eff }[\%]=\left(1-\frac{H C}{m_{\text {tota_fuel }}}-\frac{\text { CO }}{4 \cdot m_{\text {total_fuel }}}\right) \cdot 100
$$

The particle size distribution (PSD) allows an analysis of the complex mix of volatile, non-volatile species and soot agglomerates that represent the particles concentration emitted by ICEs. The PSD can show a bimodal structure with a nucleation-mode representing particles with a size smaller than $30 \mathrm{~nm}$ or for some authors than $50 \mathrm{~nm}$ [29], and accumulation-mode with particles larger than these sizes [30,31]. The nucleation-mode particles are mostly volatile or semi-volatile condensate that can nucleate to form particles with a larger size. Its formation process occurs mainly due to low combustion temperatures or during dilution and cooling of the exhaust flow $[32,33]$. The accumulation-mode is formed by agglomerates carbonaceous compounds in which volatile condensates can adhere to their surfaces. The high combustion temperature and rich equivalence ratio zones are the two main factors that favor the formation process of soot particles and can occur both in premixed and nonpremixed combustion [34,35]. The formation of the first precursors and their evolution to the final solid particles is mainly based on the following steps: pyrolysis, nucleation, surface growth, agglomeration and oxidation, in the works of J. Reijnders et al. [36] and A. Überall et al.[37] this evolution process is described in detail.

\subsection{Test design and measurement methodology}

The DMDF concept aims is to operate dual-fuel combustion over the whole engine map without exceeding some mechanical constraints defined by the engine manufacturer (PRR $<15$ bar/CAD and Pmax $<190$ bar). The combustion strategy of the concept is modified as the engine load increased, and in each strategy, the fraction of low reactivity fuel (gasoline) will allow adjusting the mixture reactivity, improving the control over combustion. Hence, during the low load operation, the concept uses a fully premixed RCCI strategy with a minimum GF of $50 \%$ to avoid excessive unburned $\mathrm{HC}$ and combustion instabilities, increasing to nearly 80 $90 \%$, as shown in Fig. 2. From medium load, the concept switches to highly premixed RCCI and dual-fuel diffusive strategy in full load operation. At high load, it was necessary to decrease the GF to $30 \%$ to avoid excessive maximum PRR. The selected operating points are shown in Fig. 2; for the fully premixed RCCI strategy the operating point is at $25 \%$ and $950 \mathrm{rpm}$ and is denoted as A950, for the highly premixed RCCI strategy the operating point is the B1500 at 50\% load and $1500 \mathrm{rpm}$; and finally for the dual-fuel diffusion strategy, two operating points, C2000 and D2200, the first at 75\% load and $2000 \mathrm{rpm}$ and the second at $100 \%$ load and $2200 \mathrm{rpm}$. Additionally, and with the purpose of making a comparison between the concepts DMDF and CDC, these same operating points were chosen in terms of load and speed in the CDC mode.

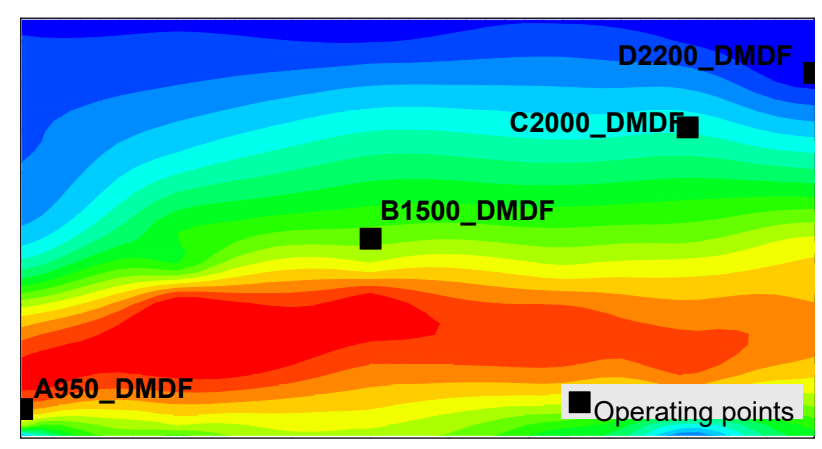

Fig. 2. Gasoline fraction (GF) rate maps used to implement the DMDF strategy and operating point selected.

Once the operating points were defined, a parametric study was carried out based on the independent modification of the EGR rate from a baseline case, which corresponds to the nominal engine configuration in each operating point. The main characteristics of these operating points are shown in Table 5, where the baseline engine settings are indicated in bold. Similar injection strategies were used in both concepts analyzed. A single diesel injection was used at the operating points C2000_DMDF, D2200_DMDF and D2200_CDC, a double diesel injection strategy at the A950_DMDF, A950_CDC, B1500_DMDF and B1500_CDC operating points. In the DMDF concept, the start of gasoline injection timing was fixed at $-340 \mathrm{CA}$ aTDC. This injection timing occurs after the intake valve opening (IVO) to avoid the fuel pooling on the intake valve seats and $8 \mathrm{CA}$ after the exhaust valve closing (EVC) to avoid short-circuit losses. In addition, the injection duration at all points of the engine map was always less than the period in which the intake valve remains open, which allows introducing all the gasoline amount into the cylinder during the intake-stroke. 
Table 5. Experimental plan for the parametric study

\begin{tabular}{|c|c|c|c|c|c|c|c|c|c|c|}
\hline Operating point & $\begin{array}{l}\text { Speed } \\
{[\mathrm{rpm}]}\end{array}$ & $\begin{array}{l}\text { IMEP } \\
{[\mathrm{bar}]}\end{array}$ & $\begin{array}{l}\text { IP } \\
{[\mathrm{bar}]}\end{array}$ & $\begin{array}{l}\text { SOIPFI } \\
{[\mathrm{CA} \text { aTDC] }}\end{array}$ & $\begin{array}{l}\text { SOI }{ }_{\text {pilot }} \\
{[\mathrm{CA} \text { aTDC] }}\end{array}$ & $\begin{array}{l}\text { SOI }_{\text {main }} \\
{[\mathrm{CA} \text { aTDC }]}\end{array}$ & $\begin{array}{l}\text { GF } \\
{[-]}\end{array}$ & $\begin{array}{l}\mathbf{m}_{\text {total_fuel }} \\
{[\mathrm{g} / \mathrm{s}]}\end{array}$ & $\begin{array}{l}\text { m } \begin{array}{l}\text { total_air } \\
{[\mathrm{g} / \mathrm{s}]}\end{array} \\
\end{array}$ & $\begin{array}{l}\text { EGR } \\
{[\%]}\end{array}$ \\
\hline $\begin{array}{l}\text { A950 DMDF } \\
\text { Fully premixed RCCI }\end{array}$ & 950 & 5.1 & 1200 & -340 & -43 & -33 & 80 & 0.27 & 18.21 & $\begin{array}{l}20 \\
\mathbf{3 0} \\
40\end{array}$ \\
\hline $\begin{array}{l}\text { B1500_DMDF } \\
\text { Highly premixed RCCI }\end{array}$ & 1500 & 12.2 & 1200 & -340 & -43 & -5 & 65 & 0.9 & 39.02 & $\begin{array}{l}40 \\
\mathbf{5 0} \\
60\end{array}$ \\
\hline $\begin{array}{l}\text { C2000_DMDF } \\
\text { Dual-fuel diffusion }\end{array}$ & 2000 & 17.82 & 1200 & -340 & - & -6 & 50 & 1.81 & 68.85 & $\begin{array}{l}36 \\
43 \\
51\end{array}$ \\
\hline $\begin{array}{l}\text { D2200_DMDF } \\
\text { Dual-fuel diffusion }\end{array}$ & 2200 & 20.8 & 1200 & -340 & - & -11 & 30 & 2.32 & 76.15 & $\begin{array}{l}20 \\
\mathbf{3 0} \\
40\end{array}$ \\
\hline $\begin{array}{l}\text { A950_CDC } \\
\text { CDC operation }\end{array}$ & 950 & 5.1 & 1200 & - & -5 & 2 & - & 0.22 & 12.75 & $\begin{array}{l}4 \\
14 \\
24 \\
\end{array}$ \\
\hline $\begin{array}{l}\text { B1500_CDC } \\
\text { CDC operation }\end{array}$ & 1500 & 12.2 & 1200 & - & -12 & -3 & - & 0.83 & 38.64 & $\begin{array}{l}0 \\
10 \\
20\end{array}$ \\
\hline $\begin{array}{l}\text { C2000_CDC } \\
\text { CDC operation }\end{array}$ & 2000 & 12.2 & 1200 & - & -25 & -13 & - & 1.71 & 67.72 & $\begin{array}{l}4 \\
14 \\
24\end{array}$ \\
\hline $\begin{array}{l}\text { D2200_CDC } \\
\text { CDC operation }\end{array}$ & 2200 & 20.8 & 1200 & - & - & -20 & - & 2.41 & 66.01 & $\begin{array}{l}0 \\
\mathbf{1 0} \\
20\end{array}$ \\
\hline
\end{tabular}

\subsubsection{Experimental procedure methodology}

The operation of a single-cylinder engine is a complex process when every engine parameter needs to be under control. Indeed, every process such as cooling or lubrication system are usually critical in this kind of test facilities. In particular, the non-research origin of the single-cylinder engine used in the current investigation implies an extra at the complexity of the tests execution. Therefore, it is very important to define a specific methodology to identify and rapidly detect possible sources of experimental errors before and during test execution. The proposed monitoring and detection protocol has been adapted from the methodology proposed in the work of J.V. Benajes et al. [38]. In Fig. 3 can be observed a scheme of the methodology followed along the present work.

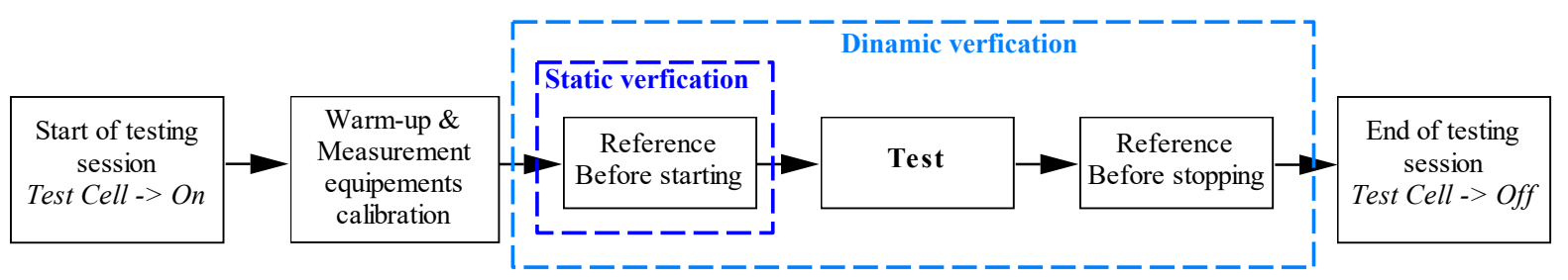

Fig. 3. Experimental procedure methodology.

As it is observed, the methodology provides two steps of verification. First step consists of a static verification and the second one consists of a dynamic verification.

- Static verification: This step consists of selecting a reference engine operation point with the aim of checking the correct operation of the different systems integrated in the experimental facility every testing day. For this purpose, the values of different parameters such as emissions, engine torque, maximum incylinder pressure, fuel supply and the fuel injection system are compared to the values measured in previous days. This verification is carried out once the engine has been heated-up. All the variables should be inside a confidence interval before proceeding with the tests campaign of the day.

- Dynamic verification: During the execution of the tests, the equipments can suffer a failure or can require a new calibration. Thus, in order to avoid this kind of dispersion or lack of reliability, the second step of verification is needed. This step will focus on the air management of the engine (fresh air mass flow, EGR rate, ...). Hence, the reference point will be set again, and the main parameters will be compared. Other errors such as mean variables measured, emissions are also checked. If the dispersion observed is inside the control limits, the tests are considered as correct. 


\section{Results and discussion}

The influence of different EGR rates over combustion process and pollutant emissions will be analyzed in this section.

\subsection{Combustion process and engine performance analysis}

Fig. 4 and 5 shows the combustion development through the RoHR profile and the in-cylinder pressure (Pcyl) for each EGR rate at each operating point.
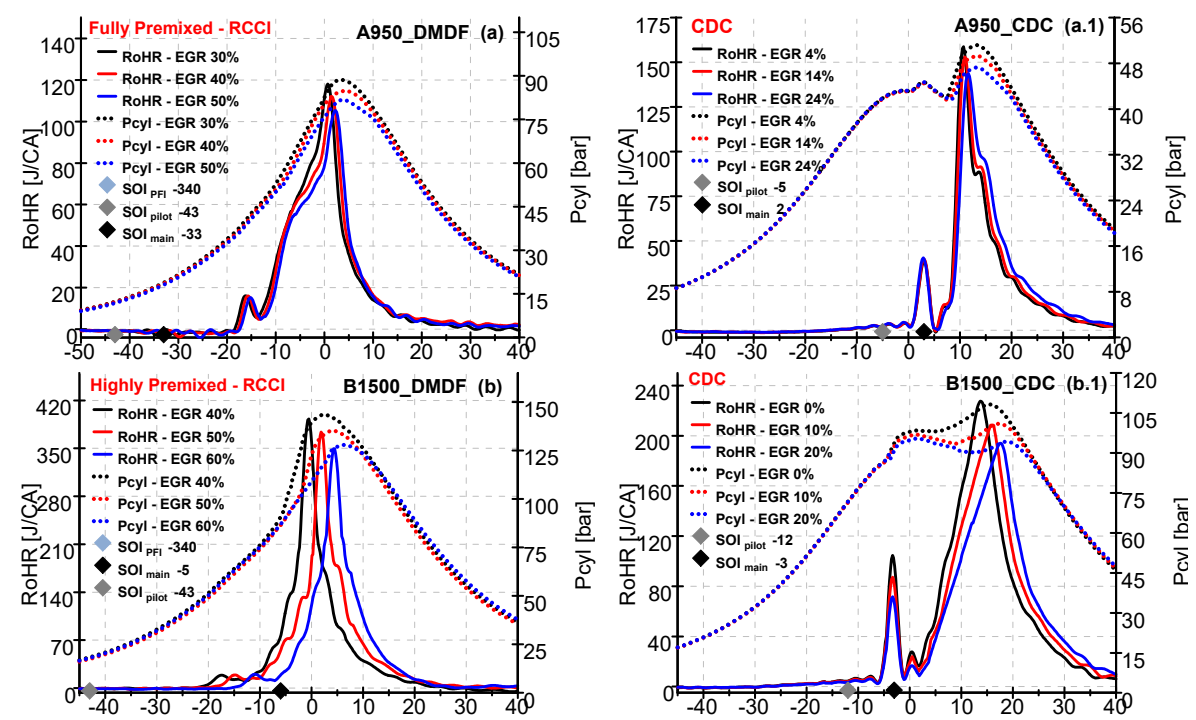

Fig. 4. Effect of EGR rate on the cylinder pressure and RoHR profile at A950 and B1500 operating points: (a)-(a.1) DMDF concept and (b)-(b.1) CDC concept.
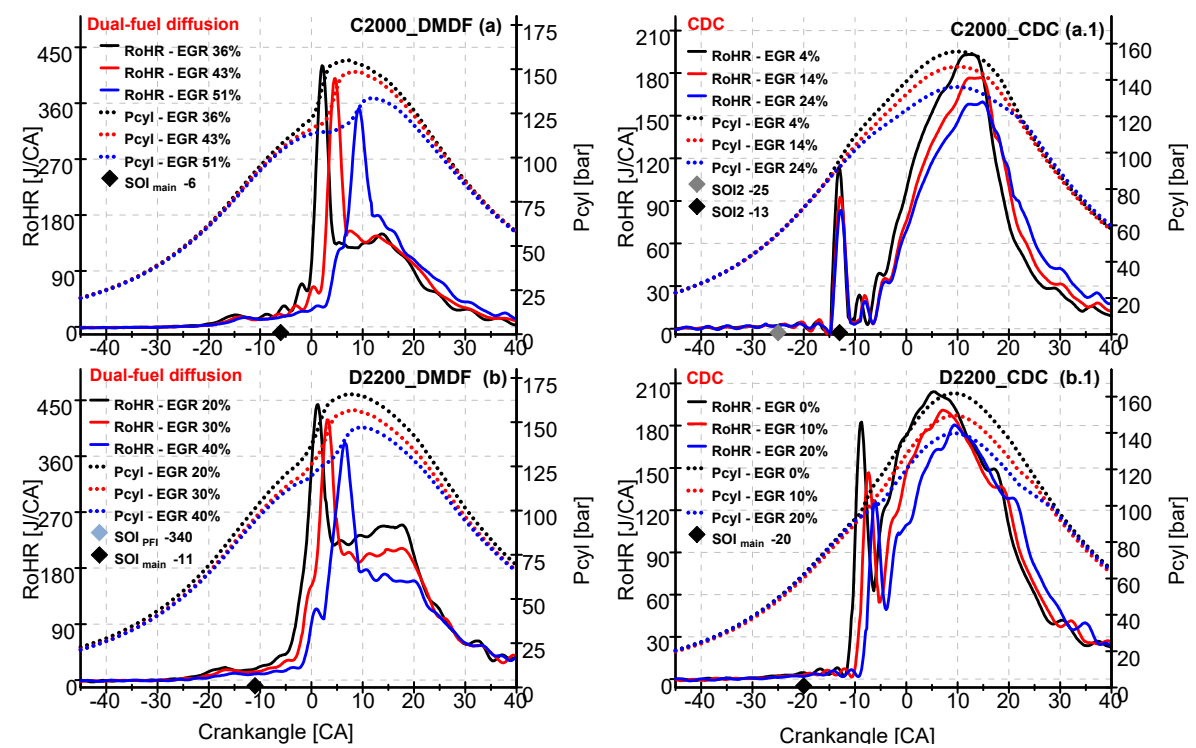

Fig. 5. Effect of EGR rate on the cylinder pressure and RoHR profile at C2000 and D2200 operating points: (a)-(a.1) DMDF concept and (b)-(b.1) CDC concept.

Specifically, Fig. 4 (a.1)-(b.1) and Fig. 5 (a.1)-(c.1) shows the temporal evolution of the combustion process in the CDC operating points. At the C2000_CDC and D2200_CDC operating point (Fig. 5 (a.1) and (b.1)) a typical ROHR profile of a single injection strategy near TDC with a sufficiently long duration is observed. From Fig. 5 (b.1), it is possible to identify the first stage or phase considered as the ignition delay, which covers the period between SOI and SoC; or more explicitly between the time at which the first fuel droplet enters the combustion chamber environment and the time where the energy release starts to grow significantly. During this phase, the fuel is injected with no apparent or very little increase in the RoHR. The second phase is the premixed combustion. This stage is characterized by the oxidation of the fuel injected during the ignition delay because it has not reached the proper conditions for autoignition. During this phase, the RoHR achieves the first peak and then the curve decreases up to a relative minimum, which determines the next combustion phase. The next phase is known as diffusive combustion. The RoHR of the diffusive combustion phase is governed by the mixture of the evaporated fuel and the air process. During this phase, most parts of the pollutants are formed. 
Finally, at A950_CDC and B1500_CDC operating points (Fig. 4 (a.1) and (b.1)) a similar diffusive combustion process is shown, but with a double injection strategy. The effect of the pilot injection can be observed with the first RoHR peak separated from the main phase. It is also appreciated that by using a pilot injection, the ignition delay is considerably reduced, so that the premixed combustion stage is greatly attenuated.

Additionally, Fig. 4 and 5 (a)-(b) are related to the DMDF concept. In this concept, to achieve the dualfuel operation in the whole engine map, apart from the GF, as explained in the previous section, the injection settings and the EGR rate vary depending on the desired engine load [12]. The different settings of these parameters are essential to achieve a stable process in each of the three combustion strategies:

- At low load during the DMDF operation, a strategy based on the RCCI concept is used. This combustion strategy can be defined as fully premixed RCCI and is characterized by an inverted V-shaped curve of the RoHR profile, as shown at the operating point A950_DMDF (Fig. 4 (a)). The combustion strategy is achieved using a double diesel injection with highly advanced injection timings. The high mixing time available prior to the SoC allows reaching low NOx and solid particle emissions. Indeed, the diesel injection timing has no direct influence on the combustion phasing as it is governed by the mixture reactivity between the fuel blend, fresh air and EGR. Moreover, this strategy allows for lower EGR rates because it is possible to achieve low PM and NOx emissions inherently.

- From $40 \%$ up to $70 \%$ load, the combustion strategy can be defined as highly premixed RCCI (B1500_DMDF operating point, Fig. 4 (b)). The highly premixed RCCI strategy presents its main difference with respect to fully premixed RCCI at the second injection timing. The SOI main is delayed towards the vicinities of the TDC. The strategy is aimed to increase the reactivity at the crevices zone, where a great quantity of gasoline gets trapped [39] with the diesel injection pilot and achieves greater control over the combustion phase with the diesel injection main. Under these conditions, the EGR rate can increase up to $60 \%$ in order to extend the premixing time and minimize the diffusion burning of the diesel fuel provided by the main injection. This allows to avoid excessive pressure gradients and the NOx emissions are still low, but particle emissions start to be penalized due to the lower mixing for the diesel main injection.

- From $70 \%$ up to full load, it is necessary to modify the injection settings defined in the RCCI strategy, as the increased in-cylinder pressure rates do not allow for an increase in the mixture reactivity before the ignition through a diesel pilot injection, due to the high chance of an onset of knocking combustion. In order to achieve the full load operation, the highly premixed strategy evolves to a more diffusive strategy. Hence, dual-fuel diffusive is achieved using a single diesel injection with a delayed SOI. From the rate of heat release standpoint, the combustion starts with a high RoHR peak due to the gasoline burning during the first diesel reactions. Immediately after this, the combustion event is characterized by a long diesel-like tail during the expansion stroke. This phenomenon is observed in the C2000_DMDF and D2200_DMDF operating points (Fig. 5 (a) and (b)). This diffusive nature observed at the RoHR provokes high levels of PM and NOx emissions compared with the previous strategies but reduces the NOx emissions compared with the CDC mode. In this strategy, the EGR rate is reduced to values close to $30 \%$ to avoid excessive particle emissions provoked by the diffusive nature of the combustion.

Before continuing with the analysis of the combustion parameters and pollutant emissions, it is crucial to comment that the total air mass flow ( $\left.\mathrm{m}_{\text {total air }}\right)$, that includes the fresh air mass flow and EGR mass flow, as well as the $\mathrm{m}_{\text {total fuel }}$ (gasoline and diesel fuel mass flow), remained relatively constants comparing with the reference point. As shown in Fig. 6 and 7 (a)-(b) and (a.2)-(b.2) in any of the four operation points, significant variation of the values of these parameters was observed. This allows concluding that both, the $\mathrm{m}_{\text {total_air }}$ and the $\mathrm{m}_{\text {total_fuel }}$, did not affect the conditions on the in-cylinder and consequently on the combustion process and exhaust emissions, leaving only the EGR rate variation as responsible for changes in emissions values.

Moreover, although the objective of this paper is not to evaluate the use of different EGR rates in terms of engine performance, the Ind. Eff and Comb. Eff analyses are important to identify whether the variation of the EGR is really viable at each operating point. As shown in Fig. 6 and 7 (b.1) and (b.3), the Comb. Eff remained relatively constant at the CDC operating points. However, at the RCCI strategy, A950_DMDF and B1500_DMDF operating points there was a slight deterioration of the combustion process as the EGR rate increased; a behavior that could be related to the decrease in the global mixture reactivity that affects the burning of part of the gasoline and diesel injected in the pilot injection that accumulates in quench areas, such as the crevices $[40,41]$.

In addition, the increase in EGR rate at B1500_DMDF, B1500_CDC, C2000_DMDF, C2000_CDC, C2000_DMDF and D2200_CDC operating points provided a slight decrease in the Ind. Eff values (Fig. $\overline{6}$ (a.3)(b.3) and Fig. 7 (a.1)-(b.1) and (a.3)-(b.3)). The results can be explained by the combustion phase delay, as shown in Fig. 4 and Fig.5. Due to the later combustion phase, the effective expansion ratio is reduced and then leads the Ind. Eff to decrease. However, the effect of EGR variations on these parameters is low (less than 5\%). 
Finally, the dual fuel strategy presents a lower combustion efficiency and indicated efficiency than the CDC mode, mainly at low load condition. The high HC and CO emissions as will be seen below are the main ones responsible for this trend. This will suppose an inefficiency of the concept, however, the benefits that are obtained considering the low NOx and PM emissions during the RCCI strategy can counteract these losses.
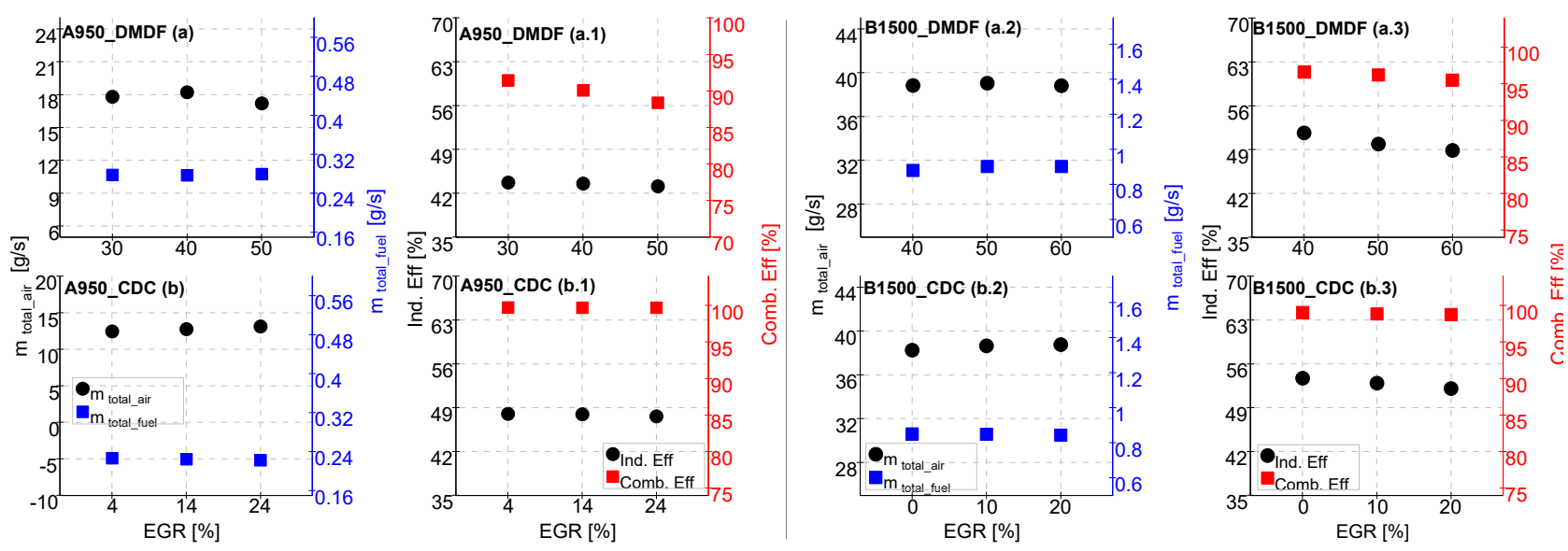

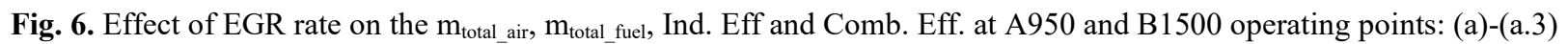
DMDF concept and (b)-(b.3) CDC concept.
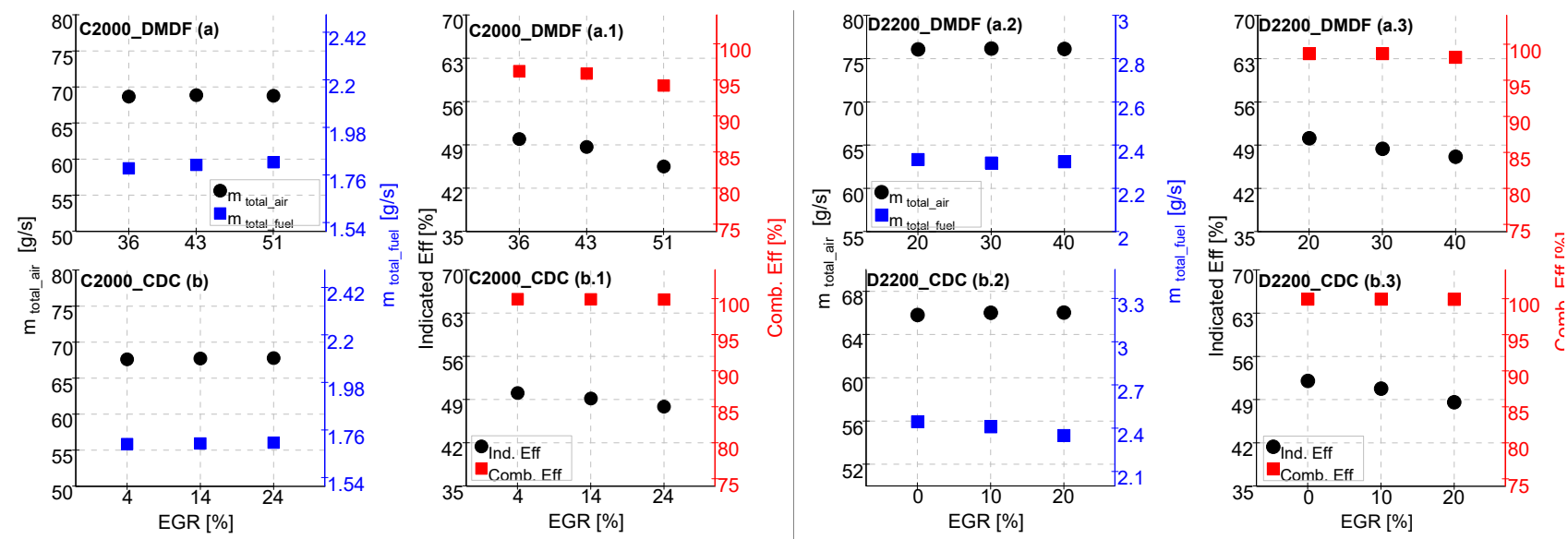

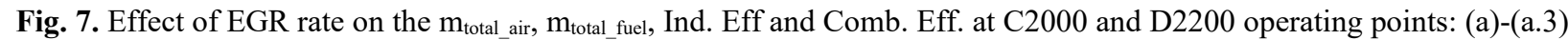
DMDF concept and (b)-(b.3) CDC concept.

As expected from the trend already observed in the RoHR profile and Pcyl (Fig. 4 and 5). On the one hand, the increase in the EGR rate decreases the in-cylinder charge reactivity, which implies a delay in the combustion phase and a decrease in the in-cylinder gas temperature, as can be observed with the increase in the CA10 and CA50 values (Fig. 8 and 9 (a)-(d)) and the decrease of Max. bulk gas temperature (Fig. 8 and 9 (a.1)-(d.1)) in all operating points. These variations were much lower in the low load operating points, both during the CDC and DMDF operation (A950_DMDF and A950_CDC), indicating a reduced impact of the EGR in these conditions. On the other hand, Fig. 8 and 9 (a.2)-(d.2) illustrates the combustion duration (CA90-CA10), the Mix. Time and the Ign. Delay, while in the fully premixed RCCI strategy (Fig. 8 (a.2)), positive Mix. Time values were observed and without significant variations. Already in the highly premixed RCCI strategy (Fig. 8 (c.2)) the Mix. Time became negative, decreasing its values as that increased the EGR, a trend that increased during the dual-fuel diffusion strategy (Fig. 9 (a.2 and (c.2)). This shows that as the engine load increases, the combustion process becomes more diffusive-like during the DMDF operation. At the same CDC operating points, the same behavior was observed, but with a more marked trend, as shown by the significant increase in the Ign. Delay values. Finally, in Fig. 8 and 9 (a.1)-(d.1), it is shown how the increase in the EGR rate decreases the Air/Fuel ratio in all the operating points. 


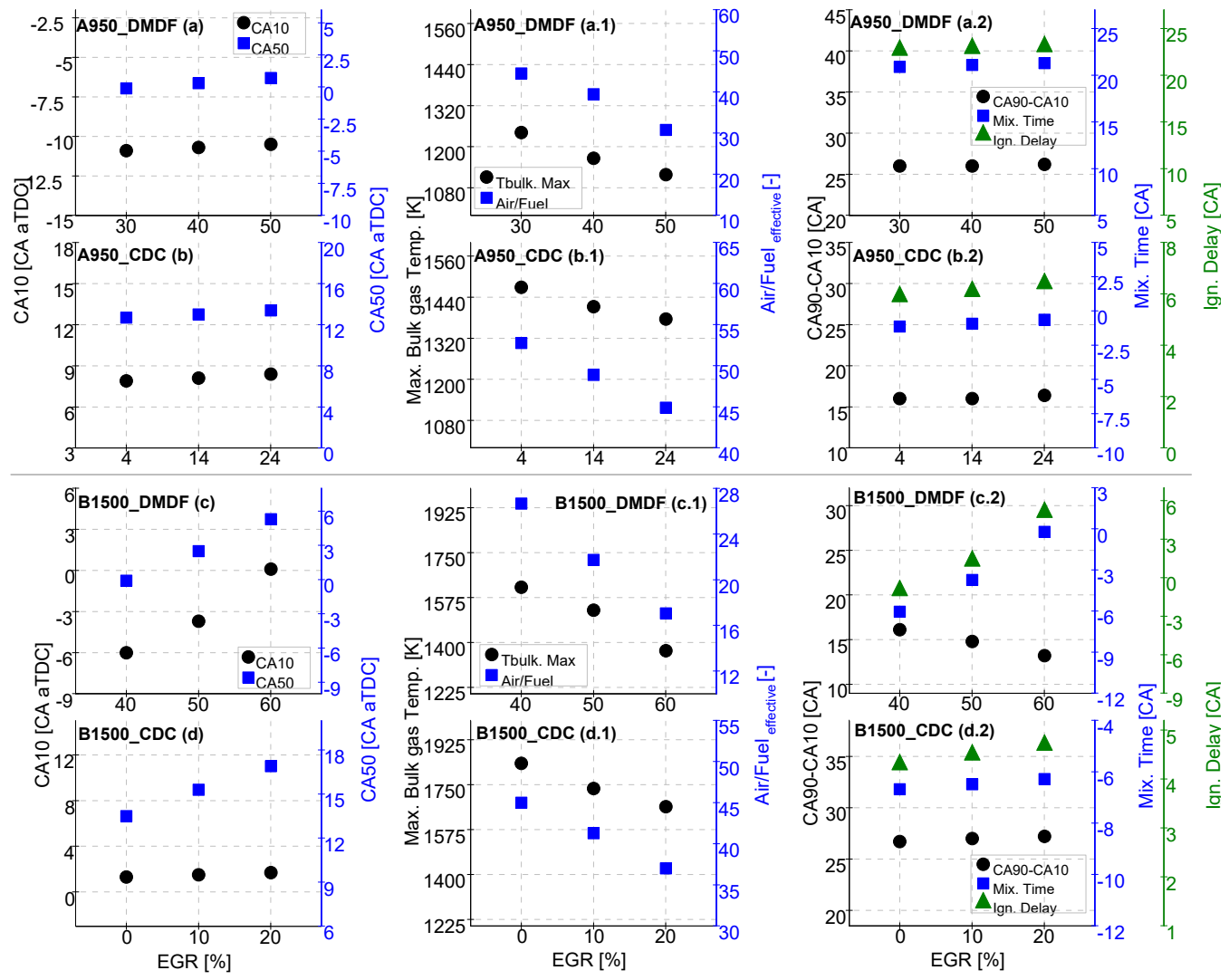

Fig. 8. Effect of EGR rate on combustion phase (CA10 and CA50), combustion duration CA90-CA10), Mix. Time, Ign. Delay Max. bulk gas Temp. and Air/Fuel ratio at A950 and B1500 operating points: (a)-(a.2) and (c)-(c.2) DMDF concept and (b)(b.2) and (d)-(d.2) CDC concept.

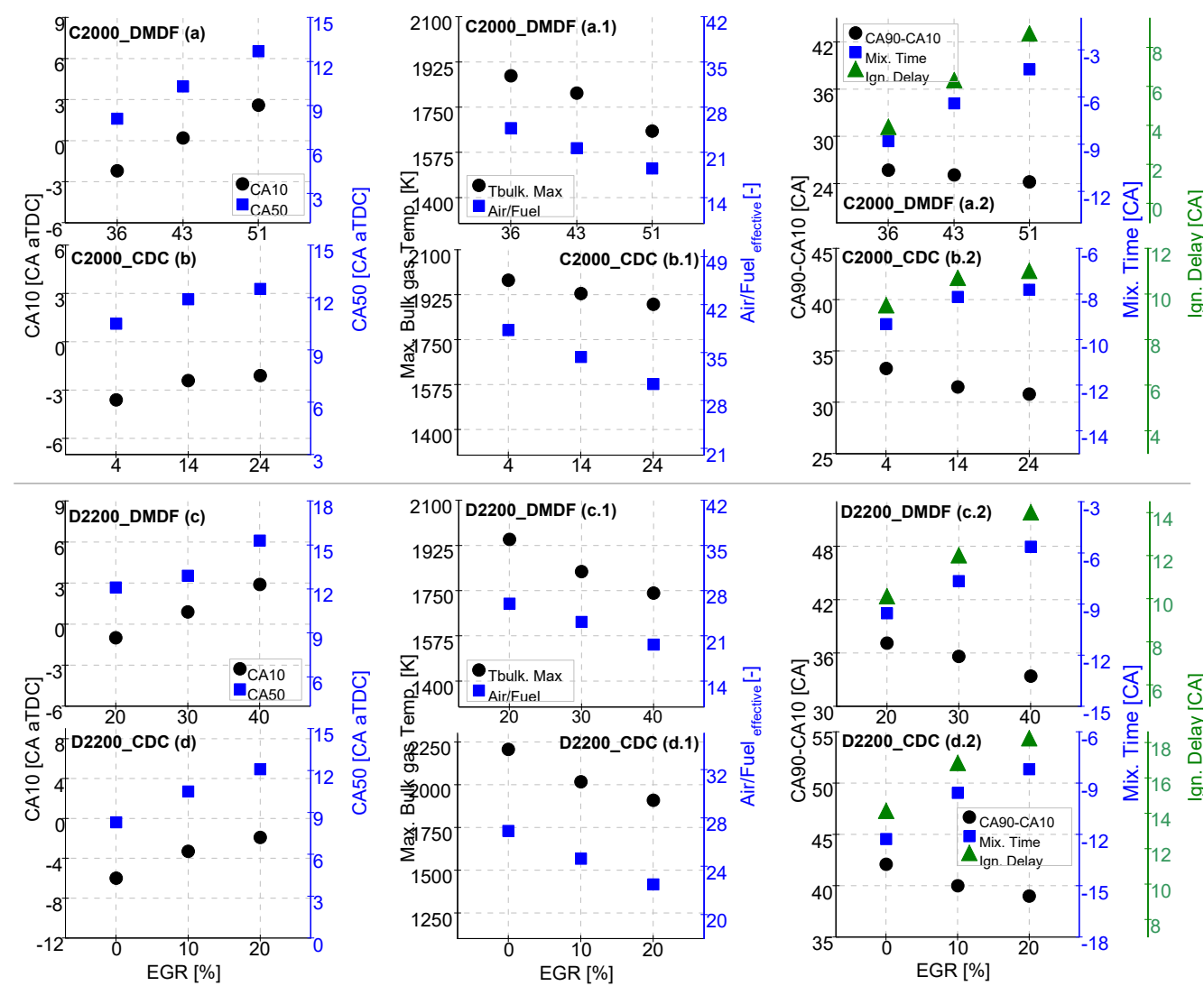

Fig. 9. Effect of EGR rate on combustion phase (CA10 and CA50), combustion duration CA90-CA10), Mix. Time, Ign. Delay Max. bulk gas Temp. and Air/Fuel ratio at C2000 and D2200 operating points: (a)-(a.2) and (c)-(c.2) DMDF concept and (b)(b.2) and (d)-(d.2) CDC concept.

\subsection{Gaseous compound emissions analysis}


With respect to the gaseous compound emissions at A950_DMDF operating point (fully premixed RCCI). Fig. 10 (a)-(a.2) shows small variations of these pollutants with the EGR variation. The increase in the EGR rate provided an increase in $\mathrm{CO}$ emissions and a slight decrease in NOx emissions. In both cases, this trend is related to the rise in Max. bulk gas temperature (Fig. 8 (a.1)) and, specifically, the CO emissions were also affected by variations in Air/Fuel ratio. Bearing in mind that the conversion process of $\mathrm{CO}$ to $\mathrm{CO}_{2}$ is limited by two factors: lower combustion temperatures, that decrease the conversion reactions and the lack of oxygen in the reaction zone [42]. In addition, NOx formation occurs from the reaction between nitrogen and oxygen during the combustion process at high temperatures and increases exponentially with the increase in combustion temperature [43]. Also, an increase in HC emissions was observed as the EGR rate increased; a trend that could be related to the reduction of the global mixture reactivity that occurs in these conditions, which limits the combustion process in the squish and crevice regions. It is important to highlight that this is due to the advanced gasoline injection and pilot diesel injection, which makes it easier for part of the fuel injected to be trapped in the crevice volume. On the contrary, at the A950_CDC operating points, the two diesel injections advanced considerably towards the TDC and as can be seen in Fig. 10 (b)-(b.2) this considerably reduces the HC and CO emissions but increases the NOx emissions due to the higher maximum bulk gas temperature in comparison with the fully premixed RCCI strategy (Fig. 10 (a)-(a.2)). These maximum bulk gas temperatures increase slightly as the EGR rate is reduced, which implies a small increase in NOx emissions.
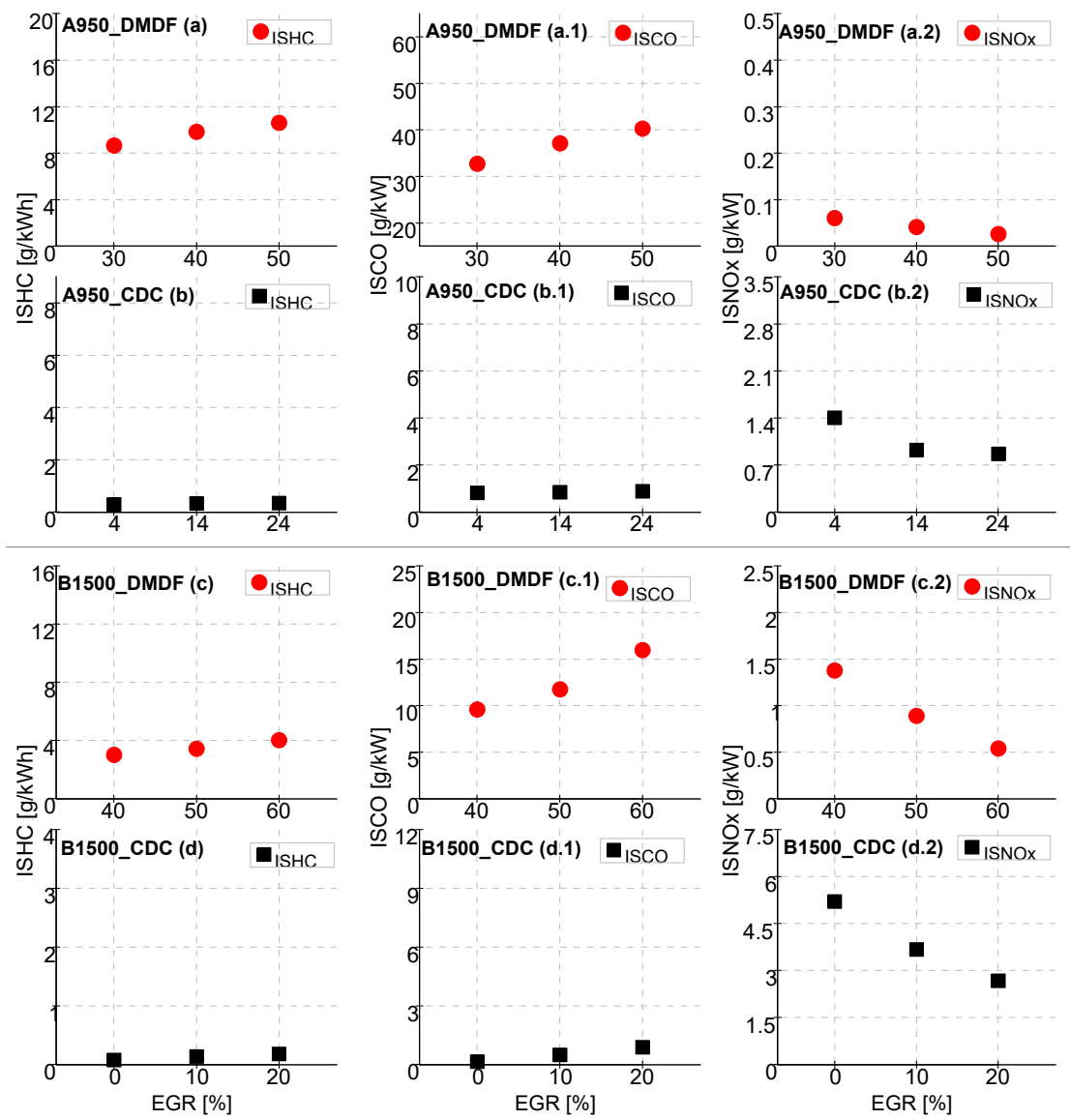

Fig. 10. Effect of EGR rate on gaseous compound emissions (HC, CO and NOx), at A950 and B1500 operating points: (a)-(a.2) and (c)-(c.2) DMDF concept and (b)-(b.2) and (d)-(d.2) CDC concept.

When switching from A950_DMDF operating point (fully premixed RCCI) to B1500_DMDF operating point (highly premixed RCCI), the combustion process becomes partially diffusive, as can be seen in Fig. 8 (c.2), through the negative Mix Time values. This is a trend that will be increasingly significant as the EGR rate decreases, that is, the coexistence period between the diesel injection and the combustion process increases with the decrease in the EGR rate. This causes higher combustion temperatures that lead to an increase in NOx emissions and a reduction in $\mathrm{CO}$ emissions, as shown in Fig. 10 (c.2) and (c.1) respectively. The HC emissions remained relatively constant with the EGR rate variation (Fig. 10 (c)), however, there was a reduction of this pollutant when compared to the A950_DMDF operating point. This is due to the lower amount of gasoline injected (lower GF value) in the B1500_DMDF operating point. Already, at the same operating point, but during the CDC mode (B1500_CDC), an increase in the Max. bulk gas temperature was observed (Fig. 8 (d.1)), which caused a reduction of the $\mathrm{CO}$ and $\mathrm{HC}$ emissions (Fig. 10 (d) and (d.1)), but the NOx emissions increased 
considerably, and their values increased even more with the reduction of the EGR rate, as shown in Fig. 10 (d.2).
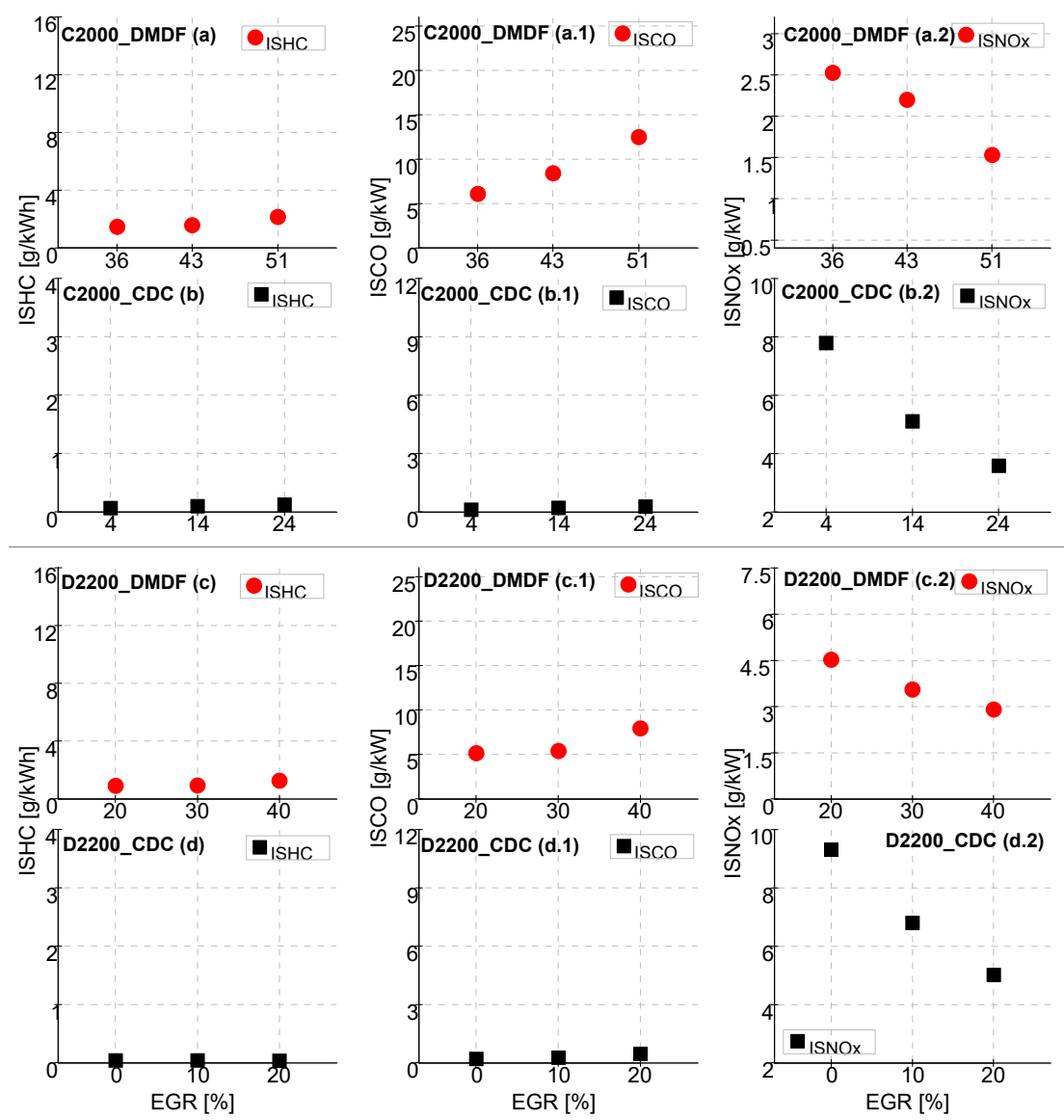

Fig. 11. Effect of EGR rate on gaseous compound emissions (HC, CO and NOx), at C2000 and D2200 operating points: (a)(a.2) and (c)-(c.2) DMDF concept and (b)-(b.2) and (d)-(d.2) CDC concept.

Finally, during dual-fuel diffusion strategy at the C2000_DMDF and D2200_DMDF operating points, a significant increase in NOx emissions (Fig.11 (a.2) and (c.2)) and a reduction in $\mathrm{HC}$ and $\mathrm{CO}$ emissions (Fig. 11 (a)-(a.1) and (c)-(c.1)) was observed in relation to the RCCI strategies. This behavior is related to the marked diffuse trend of the combustion process presented by this strategy in the DMDF concept. The reduction in the EGR rate further favors this behavior, as can be seen in Fig. 9 (a.2) and (c.2) with the decrease in the Mix. Time and the increase in the Max. Bulk gas temp in Fig. 9 (a.1) and (c.1), which greatly favors the NOx formation process. However, when compared with the CDC mode, the NOx emissions were lower. At the C2000_CDC and D2200_CDC operating points, even higher combustion temperatures and a longer combustion duration (CA90-CA10) were achieved compared to these same points in the DMDF mode, as shown in Fig. 9 (b.1)-(b.2) and (d.1)-(d.2). These parameters characterize the typical diesel diffusive combustion.

\subsection{Particle size distribution and particle number emissions analysis}

Regarding PM emissions, at A950_DMDF operating point (fully premixed RCCI strategy, Fig. 12 (a)), the PSDs show distributions dominated by nucleation-mode and without significant variations for the different EGR rates. At this operating point, the significant advance of the diesel injection increases the mixing time, which leads the local equivalence ratios towards leaner conditions, greatly limiting the solid particle formation process. In addition, the low combustion temperatures achieved in this strategy favor the formation process of nucleationmode particles. In Fig. 13 (a), a slight rise in the particles of this mode is observed with the increase in the EGR rate, which could be related to the reduction of Max. bulk gas temperature, as shown in Fig. 8 (a.1). Coincidentally, in these conditions, the highest HC emissions were also observed (Fig. 10 (a)), confirming the hypothesis, that the formation of nucleation-mode particles is mainly due to the nucleation, condensation and coagulation of the unburned hydrocarbons, which are produced due to a comparatively lower combustion temperature in premixed combustion [44]. 

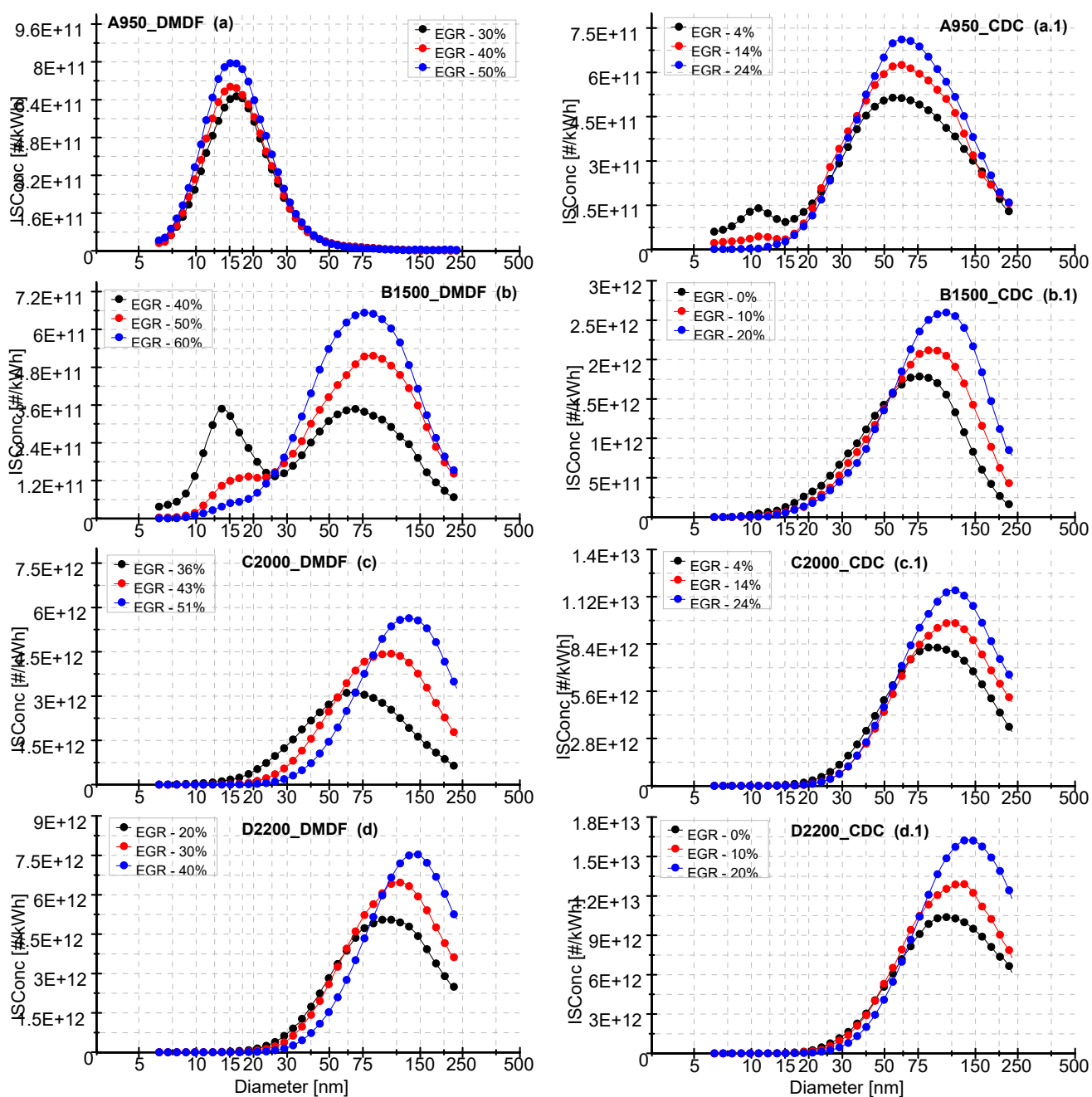

Fig. 12. Particle size distribution (PSD) for different EGR rates at each operating point: (a)-(d) DMDF operating points and (a.1)-(d.1) CDC operating points.

Continuing in the DMDF concept, at the B1500_DMDF operating point, the Mix. Time is significantly reduced, varying from zero to negative values. This results in an increase in the local rich equivalence ratios and higher combustion temperatures. Both factors favor the nuclei-precursor particles formation process. With more available nuclei particles, the surface growth and coagulation processes are intensified [45], increasing the sizes and concentration of accumulation-mode particles, as shown in Fig. 12 (b) and Fig. 13 (b). In spite of this increase in solid particle emissions at the highly premixed RCCI strategy, their values are lower than in this same operating point but during the CDC mode (Fig. 13 (b.1)). When analyzing the effect of the EGR rate variation, it is observed that in both operating points of both concepts (B1500_DMDF and B1500_CDC), the rise in the EGR rate provides an increase in the total particle emissions (Fig 13 (b) and (b.1)). This may be related to a reduction of the particle oxidation process. By increasing the EGR rate, the reactivity of the global mixture decreases, and the combustion process is delayed during the expansion-stroke (CA50 delay, Fig. 8 (c) and (d)) where temperatures are lower, limiting the oxidation process. Therefore, the PM emissions are the result of a complex balance between in-cylinder particle formation and oxidation [46,47]. 

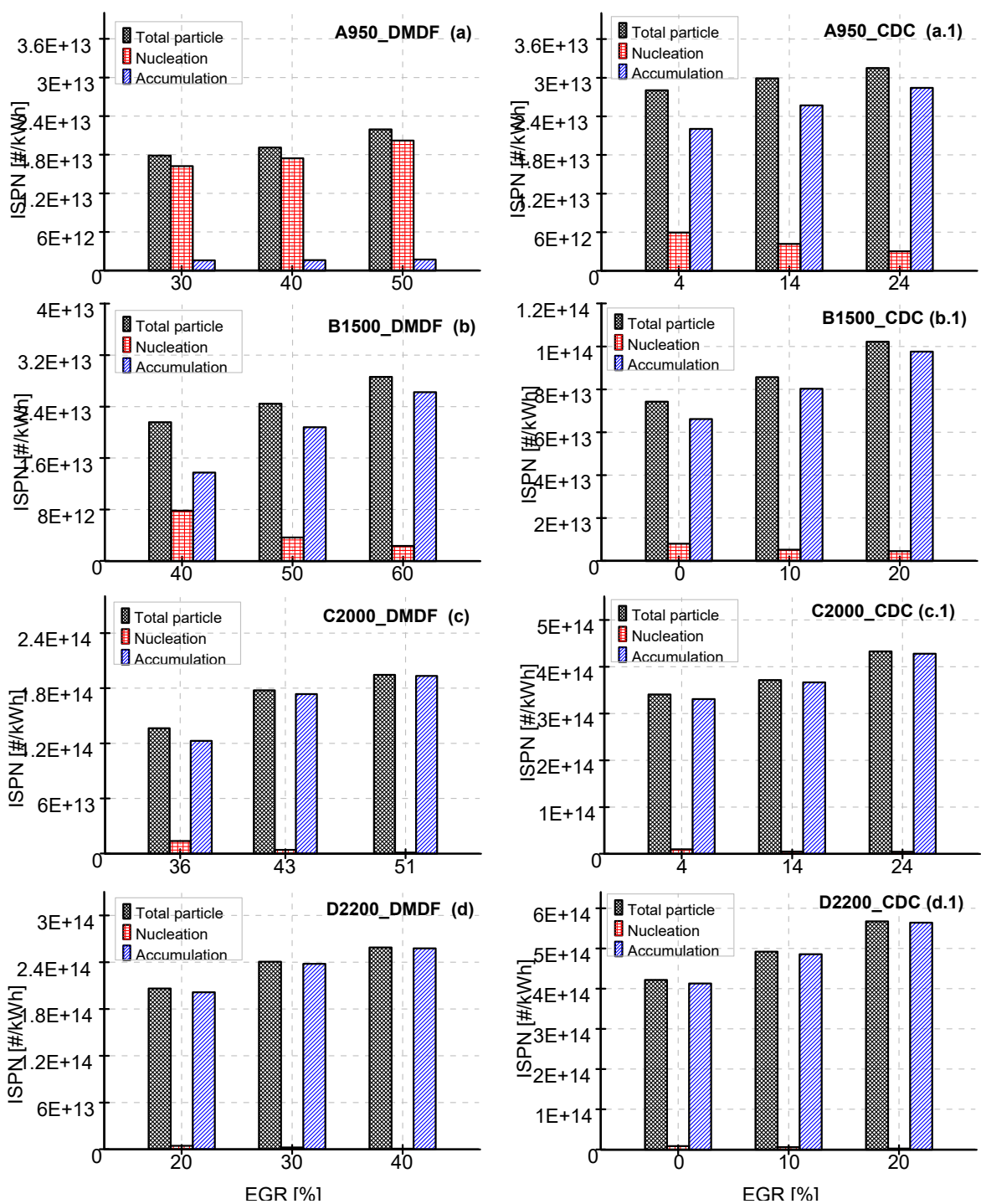

Fig. 13. Particle composition analysis for different EGR rates at each operating point: (a)-(c) DMDF operating points and (a.1)-(c.1) CDC operating points.

This phenomenon can be observed in more detail in the C2000_DMDF and D2200_DMDF operating points, in which the combustion process presents a more diffusive nature. On the one hand, there is a large increase in the time during which the fuel is burned by diffusion, as can be seen with the increase in CA90CA10 and the decrease in Mix. Time. (Fig. 9 (a.2) and (c.2)), favoring to a large extent the particle formation process and, consequently, an increase in PM emissions during the dual-fuel diffusion in relation to the highly premixed RCCI strategy, as shown in Fig. 13 (b), (c) and (d). On the other hand, the increase in the EGR rate delays the combustion phase towards conditions where the combustion temperatures are lower (Fig. 9 (a.1) and (c.1), with Max. Bulk gas temp. values) hindering the particle oxidation process and increasing the concentration of the accumulation-mode size distribution (Fig. 13 (c) and (d)). Finally, under the same operating conditions, in the dual-fuel diffusion strategy, lower particle concentrations were also observed than in the CDC mode.

\section{Conclusions}

In this study, the effects of LP-EGR on the combustion process and its consequent impact on gaseous emissions and the particle size distribution from the DMDF concept in a medium-duty CI engine were investigated experimentally. For this, a parametric study was conducted based on the independent modification of EGR rate in four operating points that encompass the combustion strategies of the DMDF concept (fully premixed RCCI, highly premixed RCCI and dual-fuel diffusion) and in equivalent operating points, in terms of load and engine speed, but in CDC mode.

At the fully premixed RCCI strategy, the combustion process was not significantly affected by the different EGR rates. The NOx emissions and concentrations of the accumulation-mode particles were extremely low, while the $\mathrm{HC}$ and $\mathrm{CO}$ emissions showed significant values that increased as the EGR rate increased. A different behavior was observed in these same operating conditions but in the CDC mode, in this case, the NOx emissions were much higher and decreased slightly with the increase in the EGR rate, while the concentrations of the 
accumulation-mode particles increased. Additionally, the fully premixed RCCI strategy showed high concentrations of nucleation-mode particles and $\mathrm{HC}$ emissions, confirming the relationship between both pollutants. At present, these particles are not included in the pollutant emissions normative, but it is undoubtedly a subject that should continue to be investigated, due to the possible inclusion of these particles in future normatives, which have evolved significantly in recent years.

At the highly premixed RCCI strategy, part of the injected diesel fuel is burned by diffusion, so that in comparison with the fully premixed RCCI strategy, PM and NOx emissions increased, but HC and CO emissions decreased. During this operation, the increase in the EGR rate caused a delay in the combustion phase in the expansion stroke where the temperatures are lower, decreasing the NOx emissions but hindering the particles oxidation process, providing an increase in PM emissions and more specifically those related to accumulation-mode. A similar trend in the emissions of these pollutants but on a larger scale was obtained in dual-fuel diffusion, due to the diesel premix elimination and the increase in the diffusion combustion process. However, the NOx and PM emissions in both highly premixed RCCI and dual-fuel diffusion strategy showed lower values than in the CDC conditions, and specifically, during the dual-fuel diffusion operation, the $\mathrm{CO}$ and $\mathrm{HC}$ emissions were similar to the diesel combustion strategy.

Finally, the results show how an appropriate EGR strategy in the DMDF concept is not only important to ensure the correct operation of each strategy involved in this concept, but also that it has a substantial impact on pollutants emission. In addition, this study shows great potential to facilitate the implementation of RCCI combustion in commercial diesel engines.

\section{Acknowledgments}

This investigation has been funded by VOLVO Group Trucks Technology. The authors also acknowledge the Spanish economy and competitiveness ministry for partially supporting this research (HiReCo TRA201458870-R).

\section{References}

[1] T. Johnson, Vehicular Emissions in Review, SAE Int. J. Engines. 9 (2016) 2016-01-0919. doi:10.4271/2016-010919.

[2] B. Rohani, C. Bae, Effect of exhaust gas recirculation (EGR) and multiple injections on diesel soot nanostructure and reactivity, Appl. Therm. Eng. 116 (2017) 160-169. doi:10.1016/J.APPLTHERMALENG.2016.11.116.

[3] P. Moulin, O. Grondin, J. Chauvin, Impact of EGR on Turbocharger Control on a Diesel Engine with two EGR loops, IFAC Proc. Vol. 43 (2010) 584-589. doi:10.3182/20100712-3-DE-2013.00108.

[4] M. Izadi Najafabadi, N. Abdul Aziz, Homogeneous Charge Compression Ignition Combustion: Challenges and Proposed Solutions, J. Combust. 2013 (2013) 1-14. doi:10.1155/2013/783789.

[5] M.M. Hasan, M.M. Rahman, K. Kadirgama, D. Ramasamy, Numerical study of engine parameters on combustion and performance characteristics in an n-heptane fueled HCCI engine, Appl. Therm. Eng. 128 (2018) 1464-1475. doi:10.1016/J.APPLTHERMALENG.2017.09.121.

[6] S.K. Pandey, S.R. Sarma Akella, R.V. Ravikrishna, Novel fuel injection strategies for PCCI operation of a heavy-duty turbocharged diesel engine, Appl. Therm. Eng. 143 (2018) 883-898.

doi:10.1016/J.APPLTHERMALENG.2018.08.001.

[7] J. Benajes, A. García, V. Domenech, R. Durrett, An investigation of partially premixed compression ignition combustion using gasoline and spark assistance, Appl. Therm. Eng. 52 (2013) 468-477.

doi:10.1016/J.APPLTHERMALENG.2012.12.025.

[8] D. DelVescovo, S. Kokjohn, R. Reitz, The Effects of Charge Preparation, Fuel Stratification, and Premixed Fuel Chemistry on Reactivity Controlled Compression Ignition (RCCI) Combustion, SAE Int. J. Engines. 10 (2017) 2017-01-0773. doi:10.4271/2017-01-0773.

[9] J. Benajes, S. Molina, A. García, E. Belarte, M. Vanvolsem, An investigation on RCCI combustion in a heavy duty diesel engine using in-cylinder blending of diesel and gasoline fuels, Appl. Therm. Eng. 63 (2014) 66-76. doi:10.1016/J.APPLTHERMALENG.2013.10.052.

[10] J. Benajes, S. Molina, A. García, J. Monsalve-Serrano, Effects of direct injection timing and blending ratio on RCCI combustion with different low reactivity fuels, Energy Convers. Manag. 99 (2015) 193-209. doi:10.1016/J.ENCONMAN.2015.04.046.

[11] J. Benajes, J. V. Pastor, A. García, V. Boronat, A RCCI operational limits assessment in a medium duty compression ignition engine using an adapted compression ratio, Energy Convers. Manag. 126 (2016) 497-508. doi:10.1016/J.ENCONMAN.2016.08.023.

[12] J. Benajes, A. García, J. Monsalve-Serrano, V. Boronat, Achieving clean and efficient engine operation up to full load by combining optimized RCCI and dual-fuel diesel-gasoline combustion strategies, Energy Convers. 
Manag. 136 (2017) 142-151. doi:10.1016/J.ENCONMAN.2017.01.010.

[13] J. Benajes, A. García, J. Monsalve-Serrano, V. Boronat, Gaseous emissions and particle size distribution of dualmode dual-fuel diesel-gasoline concept from low to full load, Appl. Therm. Eng. 120 (2017) 138-149. doi:10.1016/J.APPLTHERMALENG.2017.04.005.

[14] C.A. Idicheria, L.M. Pickett, Soot Formation in Diesel Combustion under High-EGR Conditions, in: SAE Technical Paper 2005-01-3834, 2005. doi:10.4271/2005-01-3834.

[15] J. Gong, Y. Zhang, C. Tang, Z. Huang, Emission characteristics of iso-propanol/gasoline blends in a sparkignition engine combined with exhaust gas re-circulation, Therm. Sci. 18 (2014) 269-277. doi:10.2298/TSCI130131086G.

[16] X. Gu, Z. Huang, J. Cai, J. Gong, X. Wu, C. Lee, Emission characteristics of a spark-ignition engine fuelled with gasoline-n-butanol blends in combination with EGR, Fuel. 93 (2012) 611-617. doi:10.1016/J.FUEL.2011.11.040.

[17] G. Duraisamy, M. Rangasamy, G. Nagarajan, Effect of EGR and Premixed Mass Percentage on Cycle to Cycle Variation of Methanol/Diesel Dual Fuel RCCI Combustion, in: SAE Tech. Pap. 2019-26-0090, 2019. doi:10.4271/2019-26-0090.

[18] V.Y. Prikhodko, S.J. Curran, T.L. Barone, S.A. Lewis, J.M. Storey, K. Cho, R.M. Wagner, J.E. Parks, Emission Characteristics of a Diesel Engine Operating with In-Cylinder Gasoline and Diesel Fuel Blending, SAE Int. J. Fuels Lubr. (2010). doi:10.4271/2010-01-2266.

[19] W.F. Northrop, S. V. Bohac, J.-Y. Chin, D.N. Assanis, Comparison of Filter Smoke Number and Elemental Carbon Mass From Partially Premixed Low Temperature Combustion in a Direct-Injection Diesel Engine, J. Eng. Gas Turbines Power. (2011). doi:10.1115/1.4002918.

[20] S. Curran, V. Prikhodko, K. Cho, C.S. Sluder, J. Parks, R. Wagner, S. Kokjohn, R.D. Reitz, In-Cylinder Fuel Blending of Gasoline/Diesel for Improved Efficiency and Lowest Possible Emissions on a Multi-Cylinder LightDuty Diesel Engine, in: SAE Tech. Pap. 2010-01-2206, 2010. doi:10.4271/2010-01-2206.

[21] DIN EN 228 - European Standards, (n.d.). https://www.en-standard.eu/din-en-228-automotive-fuels-unleadedpetrol-requirements-and-test-methods-includes-amendment-2017/.

[22] DIN EN 590 - European Standards, (n.d.). https://www.en-standard.eu/din-en-590-automotive-fuels-dieselrequirements-and-test-methods-includes-amendment-2017/.

[23] Instrumentation and Techniques for Exhaust Gas Emissions Measurement, in: SAE Standard J254_201106, 2011. https://saemobilus.sae.org/content/j254_201106.

[24] M. Kasper, The Number Concentration of Non-Volatile Particles - Design Study for an Instrument According to the PMP Recommendations, in: SAE Technical Paper 2004-01-0960, 2004. doi:10.4271/2004-01-0960.

[25] J.M. Desantes, V. Bermúdez, S. Molina, W.G. Linares, Methodology for measuring exhaust aerosol size distributions using an engine test under transient operating conditions, Meas. Sci. Technol. 22 (2011) 115101. doi:10.1088/0957-0233/22/11/115101.

[26] J. Bao, W.-H. Lu, J. Zhao, X.T. Bi, Greenhouses for CO2 sequestration from atmosphere, Carbon Resour. Convers. 1 (2018) 183-190. doi:10.1016/J.CRCON.2018.08.002.

[27] F. Payri, P. Olmeda, J. Martín, A. García, A complete 0D thermodynamic predictive model for direct injection diesel engines, Appl. Energy. 88 (2011) 4632-4641. doi:10.1016/J.APENERGY.2011.06.005.

[28] A.K. Agarwal, A. Pandey, A.K. Gupta, S.K. Aggarwal, A. Kushari, eds., Novel Combustion Concepts for Sustainable Energy Development, Springer India, New Delhi, 2014. doi:10.1007/978-81-322-2211-8.

[29] M. Lapuerta, O. Armas, A. Gómez, Diesel Particle Size Distribution Estimation from Digital Image Analysis, Aerosol Sci. Technol. 37 (2003) 369-381. doi:10.1080/02786820300970.

[30] W. Yinhui, Z. Rong, Q. Yanhong, P. Jianfei, L. Mengren, L. Jianrong, W. Yusheng, H. Min, S. Shijin, The impact of fuel compositions on the particulate emissions of direct injection gasoline engine, Fuel. 166 (2016) 543-552. doi:10.1016/J.FUEL.2015.11.019.

[31] P. Kumar, P. Fennell, R. Britter, Effect of wind direction and speed on the dispersion of nucleation and accumulation mode particles in an urban street canyon, Sci. Total Environ. 402 (2008) 82-94. doi:10.1016/J.SCITOTENV.2008.04.032.

[32] M.R. Saxena, R.K. Maurya, Effect of premixing ratio, injection timing and compression ratio on nano particle emissions from dual fuel non-road compression ignition engine fueled with gasoline/methanol (port injection) and diesel (direct injection), Fuel. 203 (2017) 894-914. doi:10.1016/J.FUEL.2017.05.015.

[33] Z. Zhang, T. Wang, M. Jia, Q. Wei, X. Meng, G. Shu, Combustion and particle number emissions of a direct injection spark ignition engine operating on ethanol/gasoline and n-butanol/gasoline blends with exhaust gas recirculation, Fuel. 130 (2014) 177-188. doi:10.1016/J.FUEL.2014.04.052.

[34] A.K. Agarwal, T. Gupta, A. Kothari, Particulate emissions from biodiesel vs diesel fuelled compression ignition engine, Renew. Sustain. Energy Rev. 15 (2011) 3278-3300. doi:10.1016/J.RSER.2011.04.002.

[35] F. Bonatesta, E. Chiappetta, A. La Rocca, Part-load particulate matter from a GDI engine and the connection with combustion characteristics, Appl. Energy. 124 (2014) 366-376. doi:10.1016/J.APENERGY.2014.03.030. 
[36] J. Reijnders, M. Boot, P. de Goey, Particle nucleation-accumulation mode trade-off: A second diesel dilemma?, J. Aerosol Sci. 124 (2018) 95-111. doi:10.1016/J.JAEROSCI.2018.06.013.

[37] A. Überall, R. Otte, P. Eilts, J. Krahl, A literature research about particle emissions from engines with direct gasoline injection and the potential to reduce these emissions, Fuel. 147 (2015) 203-207. doi:10.1016/J.FUEL.2015.01.012.

[38] J. Benajes, J.J. López, R. Novella, A. García, ADVANCED METHODOLOGY FOR IMPROVING TESTING EFFICIENCY IN A SINGLE-CYLINDER RESEARCH DIESEL ENGINE, Exp. Tech. 32 (2008) 41-47. doi:10.1111/j.1747-1567.2007.00296.x.

[39] M. Nazemi, M. Shahbakhti, Modeling and analysis of fuel injection parameters for combustion and performance of an RCCI engine, Appl. Energy. 165 (2016) 135-150. doi:10.1016/J.APENERGY.2015.11.093.

[40] S.L. Kokjohn, R.M. Hanson, D.A. Splitter, R.D. Reitz, Fuel reactivity controlled compression ignition (RCCI): a pathway to controlled high-efficiency clean combustion, Int. J. Engine Res. 12 (2011) 209-226. doi: $10.1177 / 1468087411401548$.

[41] R.M. Hanson, S.L. Kokjohn, D.A. Splitter, R.D. Reitz, An Experimental Investigation of Fuel Reactivity Controlled PCCI Combustion in a Heavy-Duty Engine, SAE Int. J. Engines. 3 (2010) 2010-01-0864. doi:10.4271/2010-01-0864.

[42] A. Jain, A.P. Singh, A.K. Agarwal, Effect of fuel injection parameters on combustion stability and emissions of a mineral diesel fueled partially premixed charge compression ignition (PCCI) engine, Appl. Energy. 190 (2017) 658-669. doi:10.1016/J.APENERGY.2016.12.164.

[43] C. Guardiola, J. Martín, B. Pla, P. Bares, Cycle by cycle NOx model for diesel engine control, Appl. Therm. Eng. 110 (2017) 1011-1020. doi:10.1016/J.APPLTHERMALENG.2016.08.170.

[44] B.M. Graves, C.R. Koch, J.S. Olfert, Morphology and volatility of particulate matter emitted from a gasoline direct injection engine fuelled on gasoline and ethanol blends, J. Aerosol Sci. 105 (2017) 166-178. doi:10.1016/J.JAEROSCI.2016.10.013.

[45] J. Reijnders, M. Boot, P. de Goey, Particle nucleation-accumulation mode trade-off: A second diesel dilemma?, J. Aerosol Sci. 124 (2018) 95-111. doi:10.1016/J.JAEROSCI.2018.06.013.

[46] H.J. Seong, A.L. Boehman, Studies of soot oxidative reactivity using a diffusion flame burner, Combust. Flame. 159 (2012) 1864-1875. doi:10.1016/J.COMBUSTFLAME.2012.01.009.

[47] M.P. Musculus, J.E. Dec, D.R. Tree, Effects of Fuel Parameters and Diffusion Flame Lift-Off on Soot Formation in a Heavy-Duty DI Diesel Engine, in: SAE Technical Paper 2002-01-0889, 2002. doi:10.4271/2002-01-0889. 